\title{
Entrepreneurs as Trust's Builders: An Integrated Model
}

\author{
Carmen Virues, Maria Velez, Jose M. Sanchez \\ University of Cadiz, Cadiz, Spain \\ Email: carmen.viruesvega@alum.uca.es,maria.velez@uca.es, josem.sanchez@uca.es
}

How to cite this paper: Virues, C., Velez, M. and Sanchez, J.M. (2019) Entrepreneurs as Trust's Builders: An Integrated Model. Open Journal of Business and Management, 7, 1298-1337. https://doi.org/10.4236/ojbm.2019.73091

Received: May 30, 2019

Accepted: July 16, 2019

Published: July 19, 2019

Copyright $\odot 2019$ by author(s) and Scientific Research Publishing Inc. This work is licensed under the Creative Commons Attribution International License (CC BY 4.0).

http://creativecommons.org/licenses/by/4.0/

\section{cc) (i) Open Access}

\begin{abstract}
Given trust is essential in the context of developing effective new venture, we investigate how entrepreneurs can develop a proactive role as trust builders in early stages. We review the evidences of prior studies examining the association between entrepreneur's behaviors, attitudes and characteristics and trust. By 471 empirical findings identified, we provide a wide inventory of behaviors, attitudes and characteristics that entrepreneurs could use to display their trustworthiness across stakeholders. Our conceptual model reconsiders and extends these factors and their antecedents from the model of Mayer et al., 1995, emphasizing differences across stakeholder groups and opening research venues.
\end{abstract}

\section{Keywords}

Entrepreneur, Trust, Trustworthiness, Stakeholders

\section{Introduction}

Most entrepreneurs need to interact with several stakeholders in early stages, in order to gain access to a variety of resources held by these stakeholders, overcoming their liabilities of newness [1]. When she $e^{1}$ has to be involved and collaborate with diverse stakeholders, trust is a key ingredient for reaching stable social relationships [2]. However, relatively little is known about how entrepreneurs could achieve this trust in order to get success [3].

Mayer et al., 1995 [4] provide one of the most used conceptualization of trust, defining it as "the willingness of a party (trustee) to be vulnerable to the actions of another party (trustor) based on the expectation that the other will perform a particular action important to the trustor, irrespective of the ability to monitor ${ }^{1}$ For the purpose of this paper, we use the term "entrepreneur" as "she" and "her". 
and control that other party" (p. 712). This definition applies particularly to this context because it recognizes a new venture's inherent risk characteristic for both, entrepreneur and stakeholders [5]. The article of Mayer et al., 1995 provides the foundation for evaluating how the trustee can create the level of trust needed with trustor, developing a model to represent the building of trust relationship, where decreased perceived risks by the parties would lead to more risk taking. Similarly to Lewis and Weigert, 1985 [6] whom argument that trust is based on good reasons' constituting evidence of trustworthiness, Mayer et al., 1995 clarify it and separate trust from its factors of perceived trustworthiness, such as ability, benevolence and integrity.

Most researchers have argued that trust grows gradually overtime, through joint experiences and continuous interactions [7]. From this point of view, the trustee is seen as a passive actor who can reach the status of high trust based on past personal or business relationships [8]. Traditionally, it is widely acknowledged that trust changes as people interact and gain knowledge about each other; however, early imprints have been found to have significant consequences as trustors observe the trustee and seek signs that confirm their first perception [9]. Swärd, 2016 [9] also argued that imprints are conditions or perceptions that are created during short, critical periods and remain stable over time. In this regard, trustors cognitively choose whom they will trust, basing on "good reasons" that constitute evidence of trustworthiness [10]. In early stages that can be characterized as the initial sensitive period where uncertainty is high, the trustee has to be proactive in building trust with her trustors through signaling critical characteristics in order to demonstrate her factors [11].

Translating the association between trust and factors of perceived trustworthiness into an entrepreneurial setting, there are two specific parties: a trusting party (stakeholders) and a party to be trusted (entrepreneur). Especially the entrepreneur, as intermediary assembler, needs to induce the trust of several stakeholders, and the traditional point of view seems overlook the possibility that she can actively develop trust at the inception of their relationship [11]. Consequently, the entrepreneur could build trust through certain attitudes [12], characteristics [13] and behaviors [14] that will affect the assessment of her factors of perceived trustworthiness [15]. In this regard, there are many calls to improve our understanding about how entrepreneurs can build intentionally stakeholders' trust [16] [17]. Pollack et al., 2017 [3] have corroborated that trust within this context is largely unexplored, specifically models of trust applied to the domain of entrepreneurship are uncommon and the dearth of studies related to trust in new ventures creation owing to multiple stakeholder types. These authors also noted that we know very little about what affects stakeholders' evaluation of entrepreneurs' factors. There may be relatively high degree of consensus among scholars when conceptualizing the phenomenon focus on trust output as positive factor in overcoming the risk and uncertainty among others, but there is much higher fragmentation when it comes to operational antecedents of trust 
used in empirical work due to less attention has been paid to it [17]. Consequently, our research question depicts these arguments, such as how could an entrepreneur build trust towards her from different stakeholders?

This study aims to identify what entrepreneur can do or highlight in order to foster stakeholders' trust on her. This scenario generates three interesting questions, including: 1) what are the entrepreneur's factors of perceived trustworthiness? 2) what are specific entrepreneur's characteristics, attitudes and behaviors that improve her stakeholders' valuation, in terms of trustworthiness antecedents?; and 3) is there differences across diverse kinds of stakeholders? To do this, we undertook a systematic review of the literature on entrepreneurship in order to formulate 1) a conceptual model as a set of factors of perceived trustworthiness and their antecedents that serve as tool for entrepreneurs to develop their stakeholders' trust, and 2) specific models by each stakeholder group.

Our study makes several main contributions to the literature of entrepreneurship and trust. First, the main contribution is seeking truth from facts. This review gathers a broad inventory of the entrepreneur's characteristics, behaviors or attitudes that, according with previous empirical studies, could be considered by different stakeholders as signs or signals of the entrepreneur's trustworthiness antecedents. Second, departing from model of Mayer et al., 1995 and depicting different calls for new and more detailed models adapted to different contexts [18], we translate it towards the specific characteristics of the entrepreneurial context, suggesting a model that 1) widens the factors of perceived trustworthiness, 2) details the nature and prevalence of behaviors and characteristics that induce the positive evaluation of these factors, and 3) identifies other variables that according with the empirical literature influences in this stakeholder's evaluations. Third, considering all the potential stakeholders, highlighting communalities and differences by stakeholders, given most empirical research on trust is focused on only type of stakeholder in new venture context. It permits us both to know the trustworthiness and develop specific behavioral schemas by each stakeholder groups. In this regard, our deep analysis seems to indicate that there is a common schema of factors and trustworthiness antecedents but that different stakeholders also evaluate differently them with distinctive relevance. Finally, our model suggests managerial implications. For instance, these conceptual models provide a powerful tool for understanding the nature on creation of the trust, which become the basis for developing effective relationship with stakeholders. A key message for entrepreneurs, then, is this: if you need to build trust with several stakeholders around of you, you should signal specific behaviors, characteristics and attitudes in order to show your factors of perceived trustworthiness.

This research proceeds as follows. In the next section, we examine the relevant literature on trust, entrepreneurship and stakeholder theory. Next, we describe the systematic literature review procedures as well as analyze a set of findings using a suit coding guideline. We then present the results, followed by an interpretation of them. Finally, we consider the implications of this study followed by 
suggestions for possible future research directions.

\section{Background}

Starting a new venture is a challenge, mostly in a poorly structured environment and where entrepreneurs may have few resources. Thus, she has to face up to marshal a wide range of resources that need in order to create and/or discover and exploit new opportunities [19]. In this regard, entrepreneurs spend significant amount of time on identifying the new contacts that will provide these critical resources to begin the venture, particularly in the first stage [1].

In this vein, increasingly the entrepreneur is recognized to be a social individual, operating and engaging with and in the social, to be both part and process of the social milieu [20]. The entrepreneur works at ecosystems, in communities and spaces to learn, work, and do economic and non-economic interchanges with stakeholders around them. The term of stakeholder refers to "any group or individual who can affect or is affected by the achievement of the firm's objectives" [21]. By establishing viable business relation with diverse stakeholders, she mobilizes resources, gets support and help, and creates legitimacy that allow for having in successfully launching a new venture [22]. According to the stakeholder theory, the long-term performance of a new venture depends on the effectiveness and sustainability of its relationship with these stakeholders [23]. Specially, entrepreneurs rely on several potential stakeholders such as customers, suppliers, investors, among others [24].

Several researchers have suggested that resources reaching depend on direct and indirect ties with these stakeholders, which is rooted in trust [25]. Thus, these relationships are not only about whom you are, whom you talk to, but perhaps more importantly, whom you trust [26]. Entrepreneurs need to trust others, but primarily they need to serve as trustees in order to form and growth their projects [27]. The entrepreneur could play a role as orchestrator, facilitating this process by focusing on trust that is essential for developing and maintaining business relationship because it affects the depth and richness of exchange relations [28]. Trust encourages people to support entrepreneur's activities in a way that might not be possible if trust did not exist [29]. This is because trust has a positive role to play in reducing the complexity of business operations, in allowing business relationship with strangers, in lowing transaction cost for business, and in facilitating network activity [30].

Trusting is a social process, entails behaviors such as signaling among others, can be reframed as studies of how trustors and trustees generate and "process" (i.e., handle) information in order to produce the outcome of trust [31]. Important trust drivers are the factors of perceived trustworthiness, differing from trust per se [4]. When the perceived trustworthiness matches the requirements of a specific situation, one may expect that the trust formation process could be accelerated and the trustor reaches a trust decision sooner. The model of Mayer et al., 1995 separated trust from these factors of perceived trustworthiness, such 
as ability, benevolence and integrity. Ability is the group of skills, competencies, and characteristics that enable a party to have influence within some specific domain. Benevolence is the extent to which a trustee is believed to want to do good to the trustor, aside from an egocentric profit motive. Integrity is the perception that the trustee adheres to a set of principles that the trustor finds acceptable. In turn, each one of these factors will depend on several trustworthiness antecedents in terms of the entrepreneur's characteristics, behaviors or attitudes that could be allocated attention to and interpreted by stakeholders as signs or signals to build trust [14]. Especially cognitively processed these antecedents, as signs and signals, become cues for certain trust warranting properties through her factors perceived. Likewise, there will be trustworthiness antecedents that will feed on diverse factors, like a root tree. The factors of perceived trustworthiness are widely considered to be multi-dimensional [4], and which dimension is most relevant in a particular situation can vary as a function of the nature and depth of the interdependence in a given relationship [18]. For example, we could expect that different surrounding stakeholders will look for different entrepreneurs' signals as trustworthiness antecedents.

In this vein, trust is an evidentiary phenomenon, where the trustor adjusts his/her trust in the trustee on the basis of observed actions and his/her interpretation [32]. Traditionally, high levels of personal trust mainly reflect repeated positive experiences made over time and longstanding relations, where person has come to know each other [33]. Similarly, Blumberg et al., 2015 emphasize its development is characterized by gradual increase, through the following proverb "it takes years to build up trust, and only seconds to destroy it". Scholars have most often described trust development as a relatively passive process of gathering data about other people's trustworthiness by watching their behaviors in various situations, without considering the intentional actions that can build trust [34]. However, Lewicki and Brinsfield, 2015 [35] highlighted that some researchers examined trust through making a series of rapid judgments, for example, trust in romantic relationships. In this sense, Meyerson et al., 1996 [36] analyzeswift trust in temporary groups, where there is not time to engage in the usual forms of activities that contribute to the development of trust in more traditional organization. These authors thereby emphasize that to trust and to be trustworthy means that people have to wade in on trust rather to wait while experience gradually shows who can be trusted. This process not attempt to as "love at first sight" but neither to build trust gradually due to the entrepreneur has lack resource to keep over time. For example, Lewicki and Bunker 1996 [37] described a basic level of trust as calculus-based trust that is based on a relatively rational decision making process, which usually develops first in a relationship. Similarly, other authors suggest that these judgments are shaped quickly through the other party's dress, uniform, gender, race, culture and other situations [38]. In this line, we specially look at early stages of the new venture evaluation process, which could depend on a set of cues signaled by entrepreneur that lead stakeholders to quickly deduce that they can trust her [39]. 


\section{Method}

This paper forms part of a broader project centered on entrepreneurs' trustworthiness. As a first step, and according to Pittaway and Cope, 2007 [40], we conducted a systematic literature review (SLR) because it is an appropriate methodological approach within the field of entrepreneurship research, and is especially useful where large volumes of evidence over long time periods are involved [41] (Table 1).

This SLR involves several steps namely: identifying relevant works, summarizing the evidences and interpreting findings [41]. To ensure reasonably complete coverage of the entrepreneurship literature, we included all journals that are considered the premier outlets within entrepreneurship scholarship according to the Academic Journal Guide 2015 published by the Chartered Association of Business Schools (CABS). To gain a sense of an update and comprehensive views of majority trustworthiness antecedents, we conducted a review that covered the period between 2000 and 2015. In fact, there is a notable growth in the number of publications focused on entrepreneurship from 2000 to 2015 (source ABI/info data base).

Table 1. Stages in the review and analyses process.

StageDescription

1) According to Academic Journal Guide 2015 (CABS), all journals in entrepreneurship area search were considered ${ }^{\dagger}$

2) The search was restricted to articles published in the period between $01 / 01 / 2000$ and $10 / 04 / 2015$

3) Within the selected journals were conducted a search using the keyword trustworth* in the "All Text" field

4) The above searches resulted in a total of 587 discrete articles

5) Each resulting article was then examined by at least 2 authors and a set of criteria was applied

6) Papers were reviewed using a thematic reading guide, adapted from Henry and Foss, 2014. See Annex 1

7) Subsequently, this in-depth reading led to exclude articles where the criteria did not meet. All authors discussed the final sample of 55 articles

8) All authors built a coding guideline, see Annex 2

9) The findings were grouped by at least two of the authors according to this coding guideline

10) Final results were discussed by all authors

11) Final tables summarized these results; see Tables 3-8

${ }^{\dagger}$ Entrepreneurship Theory and Practice; Journal of Business Venturing; Strategic Entrepreneurship Journal; Entrepreneurship and Regional Development; Family Business Review; International Small Business Journal; Journal of Small Business Management; Small Business Economics; International Journal of Entrepreneurial Behaviour and Research; International Journal of Entrepreneurship and Innovation; Journal of Family Business Strategy; Journal of Small Business and Enterprise Development; Venture capital: an international journal of entrepreneurial finance; International Entrepreneurship and Management Journal; Journal of Enterprising Culture; Journal of Entrepreneurship; Journal of International Entrepreneurship; Journal of Small Business and Entrepreneurship; Social Enterprise; World Review of Entrepreneurship Management and Sustainable Development. 
Using the electronic databases such as ABI/Inform, EBSCOhost, Elsevier Science Direct, Google Scholar, JSTOR and PsycInfo among others, a manual search was conducted for each journal considered. In particular, we have conducted "within-journal" searches using "trustworth" as only keyword, yielding a total of 587 articles (see Table 2). In these articles, a scrutiny was done based on its abstract, searching also in the full text. Each article was reviewed by the research team to ensure the inclusion of the relevant articles that met three criteria: 1) only empirical articles; 2) studies that examine the interpersonal and inter-organizational trust in an entrepreneurial context in early stages; and 3) studies that operationalized entrepreneur as the trustee. Thus, our preliminary data set included 139 articles meeting all of our selection criteria.

In these articles, we sought entrepreneur's behaviors, attitudes and characteristics that increase the stakeholders' trust on her, looking at the evidences, like survey measures and empirical findings. According to Henry and Foss, 2014, we constructed a thematic reading guide and devise an appropriate system to summarize the main content of these relevant papers (see Annex 1). This guide includes author, year, journal, theory, trust definition, method, sample, empirical findings, finding's source, country, type of stakeholder involved in the study and comments about each article. Consistent with these authors, we early decided on the literature review process to use a manual coding system because not all of the variables explored were "explicit", and thus required reading, re-reading and additional reflection on the part of the team research. Two researchers of the team assessed each paper independently at the same time as A (should be in shortlist), B (doubt), or C (should not be in shortlist). B listed papers were further discussed and then sorted as A or C listed papers. Consistent with Dawson and Mussolino, 2014 [42], to categorize these articles, the two members examined and reviewed the entire article, using the exclusion criteria in a conservative fashion favoring inclusion rather than exclusion. Consequently, 84 articles were omitted. After that, a final list comprising 55 papers were re-analyzed in detail to identify the empirical evidences offer by them about entrepreneurs' behaviors, attitudes and characteristics that make them trustworthy. This process was developed at the same time by all the members of the team to avoid potential subjective angle from each one. To achieve a consensus on the finding identified by each member, the empirical findings were discussed for the whole team, paying special attention when a disagreement arose. Thereby this resulted in $471 \mathrm{em}$ pirical findings.

By searching for a parsimonious set of entrepreneurial behaviors, we created a coding guideline (see Annex 2) doing several steps. First, we listed and defined the trustworthiness antecedents drawing extensively on Maxwell and Lévesque's (2014) behavioral trust schema and Butler's (1991) trust inventory. Likewise, nine "bases" of trust of Gabarro, 1978 and conditions of trust Jenning, 1971, which were included into the article of Butler, 1991, were also considered. Second, these antecedents were related with factors of perceived trustworthiness, 
Table 2. Articles published in each journal from 2000 to 2015

\begin{tabular}{|c|c|c|}
\hline Journal & $\begin{array}{l}\text { Total articles } \\
\text { with trustworth* }\end{array}$ & $\begin{array}{l}\text { Articles used } \\
\text { in this study }\end{array}$ \\
\hline Entrepreneurship Theory and Practice & 81 & 5 \\
\hline Journal of Business of Venturing & 60 & 5 \\
\hline Entrepreneurship and Regional Development & 50 & 3 \\
\hline International Small Business Journal & 44 & 6 \\
\hline Family Business Review & 43 & 1 \\
\hline Small Business Journal & 30 & 2 \\
\hline Journal Small Business Management & 29 & 3 \\
\hline International Journal of Entrepreneurial Behaviour and Research & 29 & 2 \\
\hline Journal of Family Business Strategy & 29 & -- \\
\hline Journal of Small Business and Enterprise Development & 28 & 4 \\
\hline International Entrepreneurship and Management Journal & 26 & 4 \\
\hline Journal of Enterprising Culture & 26 & 4 \\
\hline Venture Capital: An International Journal of Entrepren. Finance & 25 & 5 \\
\hline Journal of International Entrepreneurship & 25 & 2 \\
\hline Journal of Small Business and Entrepreneurship & 18 & 4 \\
\hline Journal of Entrepreneurship & 17 & 3 \\
\hline Strategic Entrepreneurship Journal & 13 & -- \\
\hline Social Enterprise & 13 & 2 \\
\hline World Review of Entrepreneurship Management and Sust. Devt & 1 & -- \\
\hline TOTAL & 587 & 55 \\
\hline
\end{tabular}

ability, benevolence or integrity, using the definitions, synonyms, and examples from the conceptual article of Mayer et al., 1995. Third, using this guide we associate former 471 empirical findings in each antecedent and factor. To avoid the potential ambiguity of this categorization process and in order to improve coding reliability, three researchers together categorized all findings with their knowledge, experience, point of view, and without losing sight of the context where was discovered each finding and measurement. This process involved several iterations seemed the process that was described before, including meetings, discussions, rethinking and putting together all views. Due to their meanings were very similar each other, with some level of overlapping, we had to set out sense of each one of us to avoid misunderstandings. Differences were discusses until agreement was made on any aspects, revisiting previously coded paper again in the light of these discussions.

In the next section we describe the model about entrepreneur's trustworthiness obtained from our review. This model clearly differentiates factors from trustworthiness antecedents that contribute to them, and it also differentiates trust from its antecedents such as factors. 


\section{Results}

Our literature review reveals a comprehensive inventory of behaviors, attitudes and personal characteristics of the entrepreneur, building stakeholders' trust on her. Tables 3-5 show these findings gathered by antecedents of trustworthiness factor from the model of Mayer et al., 1995 trustworthiness factors, illustrating, in this way, specific aspects that, according to the empirical finding of previous literature, have led stakeholders to perceive the entrepreneur's ability, benevolence and integrity.

Table 3. Ability.

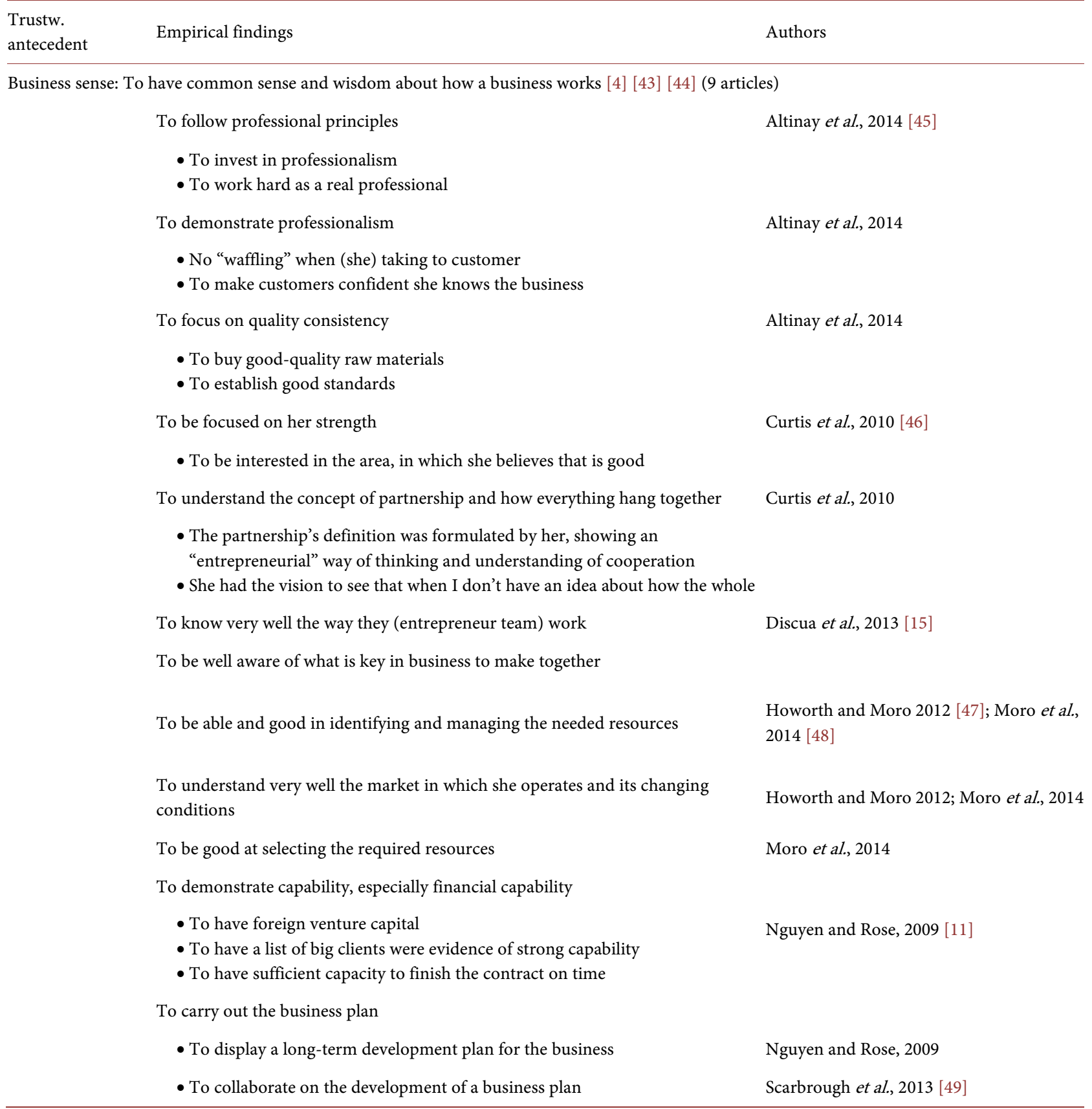




\section{Continued}

To have very high presence of specific characteristics as entrepreneurial personality

To focus on specific aspects

- Her vision

- Her ability to execute and take risk

To have good ideas

- Her ideas are fit my own (of the venture capital) way of doing business and also good

To do things she does simply make sense

To show how she thinks in business

To be able to create a business out of nothing and make it successful

To make evident a sustainability of the business

Capable experience: To demonstrate relevant work and/or training experience [4] [14] (15 articles)

To develop best practice presentations

To evidence expertise

To possess professional identity

To expose training experience

- She has seen the action in real life and how is developed the language with her team members

To demonstrate experience

- Experience in business, new ventures and team experience

- To indicate successfully exiting previous investment(s)

- The number of employees is closely related to trustworthiness, accurate self-assessment, achievement orientation, and conflict management

- To be a private entrepreneur before

- To be very successful in the past

- To carry out previous acts and achievements

- To have a prior record of performance

- To be repeat or experienced, with international marketing and sales experience

- To evidence that she worked well

- To share experiences during assignment

- Long work experience in large reputable organizations

- To demonstrate relevant work

- To have personal record and business's technical track record

She already had 15 years' experience and good business track record, so she talked about that with them (venture capitalist)

To make clear to her potential customers that she has big business groups as clients
Payne et al., 2009 [50]

Schwarzkopf et al., 2010 [51]

Schwarzkopf et al., 2010

Curtis et al., 2010

Discua et al., 2013

Discua et al., 2013

Nguyen and Rose, 2009

Bergh et al., 2011 [52]

Bergh et al., 2011

Altinay et al., 2014

Maxwell and Lévesque, 2014 [14]

Discua et al., 2013; Kelly and Hay, 2003 [53]

Bergh et al., 2011 Scarbrough et al., 2013; Discua et al., 2013;

Kelly and Hay, 2003 [53]

Rhee and White, 2007 [54]

Curtis et al., 2010

Batterink et al., 2010

Schwarzkopf et al., 2010

Bergh et al., 2011

Lehto, 2015 [55]

Maxwell and Lévesque, 2014

Jack et al., 2008; Sengupta, 2011 [56]

Nguyen and Rose, 2009 [11]

Lopes et al., 2009 [57] 


\section{Continued}

To give to know her work, so some of her clients did not have too much uncertainty to invest in her company

To get higher-status partnership

- To establish alliances and partnerships with larger and
Lopes et al., 2009

Lopes et al., 2009

higher status firms.

Functional/specific competence: To control knowledge and skills related to a specific task and competence to develop the best possible it [14] [43] [44] (19 articles)

To possess competence (capable to act properly and with a good result while solving problems in a complex, real-life environment)

- To be very good at doing his job and to evidence the quality of your work

- To possess extensive capabilities

- To demonstrate she is able to respond to client's needs

- To satisfy the client at the moment and exchange the material immediately

- To hand-on solving problem instead of hand-off market contracting approach

- To work harder- "to meet expectations"

- To be able to deliver what she considered his customers wanted-cheaper quality products

- To show clarity and efficiency of activity through new buildings, machines and systems

- To have ability to perform well a task

- To give input, accurate feedback and advice during presentations and discussions

- To know very well their (entrepreneur team's member) capabilities

- To do things right

- To have personal and professional background

- To display relevant technical and/or business ability

To have knowledge (to recall facts, concepts, principles and procedures within certain domains)

- To have a very good formal education (secondary and university levels)

- To master good English language communication skills

- To use language effectively

- To be intellect

- To possess specific knowledge and business

- To possess extensive knowledge of the product

- To show what she knows and she has dedicated to study (e.g. knowledge)

- To have a good faith on the entrepreneur team members' knowledge

- To be good in something (e.g. negotiation)
Bowey and Easton, 2007 [58];

Sengupta, 2011; Howorth and

Moro, 2012

Jack and Anderson, 2002 [59]; Howorth

and Moro, 2006; Lopes et al., 2009;

Howorth and Moro, 2012

Lopes et al., 2009

Lopes et al., 2009

Nguyen and Rose, 2009

Curtis et al., 2010

Holt and Macpherson, 2010 [60]

Holt and Macpherson, 2010

De Clercq and Sapienza, 2006 [61]

Bergh et al., 2011

Bergh et al., 2011

Discua et al., 2013

Scarbrough et al., 2013

Maxwell and Lévesque, 2014

Jenssen and Kristiansen, 2004; Payne et al., 2009

Altinay, 2008 [62]

Payne et al., 2009

Bergh et al., 2011

Jones and Rowley, 2011 [63]

Discua et al., 2013 


\section{Continued}

- To domain a knowledge

Scarbrough et al., 2013

To display her own skills

(to have acquired a proficiency in the execution of operations to achieve a certain goal state)

Bowey and Easton, 2007; Scarbrough et al., 2013

- To be equipped with technical skills to handle the daily operations.

Jean and Tan, 2001 [64]; Payne et al., 2009; Bergh et al., 2011; Sengupta, 2011

- To have leadership ability

Payne et al., 2009

Interpersonal competence: To possess relational skills [4] [43] [44] (5 articles)

To talk about almost anything in the network (communication)

Bergh et al., 2011

Body language

Bergh et al., 2011

To be able to convince

Curtis et al., 2010

- To be capable to convince customers about her products and services

Jansson, $2011[65]$

To foster external legitimacy

Jansson, 2011

- To explain and clarify all possibilities and advantages, that could offer her new product or service

To develop a process of persuasion

Jansson, 2011

To keep someone who was respected

MacDougall and Hurst, 2007 [66]

To develop gestural language

Lee and Jones, 2008 [67]

- Eye gaze and changes in facial expression

Judgment: To make accurate decisions [14] [44] (1 article)

To make accurate and objective decisions

Maxwell and Lévesque, 2014

Table 4. Benevolence.

Trustworth. antecedent

Empirical findings

Authors

Accuracy: To provide adequate, truthful and timely information [14] (11 articles)

To switch considerable information and experience in the networking exchanges

Cruickshank and Rolland, 2006 [68];

Moro et al., 2014

To develop intensive communication and interaction

Nguyen and Rose, 2009

To exchange high-quality information

Jack et al., 2008; Moro et al., 2014 [48]

- To timely exchange information

Batterink et al., 2010; Scarbrough et al., 2013; Maxwell and Lévesque, 2014 [14]; Moro et al., 2014;

- To show willingness to share relevant information

Scarbrough et al., 2013;

- To present that information in a skillful manner

Scarbrough et al., 2013

- To provide accurate, fine-grained, completeness and adequate communication

Batterink et al., 2010; Moro et al., 2014; Jonsson, 2015 [69]

To develop effective strategies, such as an honest communication

Kelly and Hay, 2003; Amatucci and Sohl,

- To be honest in disclosing all relevant information to investors 2004 [70] 


\section{Continued}

To be communicative

Maxwell and Lévesque, 2014

- To offer truthful information

To use effectively different patterns of communication

Lee and Jones, 2008

- To develop face to face communication

It helps her maintain close bonds and share common goals while clarifying

complex tasks and meanings

- To use gestural, assertive and expressive language

It facilitates efficient understanding between actors and her.

- To employ a code

It provides an interpretive system for ascertaining meaning and understanding

of where communicative value lies

- To utilize narratives, stories and jokes

It facilitates the "ebb and fow" of face-to-face communication for both groups

- To use on-line communication

Improving online formatting as well as assertive/concise language helps the

clarity of electronic messages

Availability: To be physically present when is needed, approachable and reachable [4] [44] (5 articles)

To facilitate spatial and cultural proximity

To make easier mental proximity

To promote physical proximity

To receive customer at anytime

- The customer often comes to her without reasons related to work

To invite potential partners to visit her premises

To visit the partner's facilities
Jansson, 2011

Totterman and Sten, 2005 [71]

Totterman and Sten, 2005 [71];

Van Gelderen, 2010 [72]

Presutti et al., 2011 [73]

Nguyen and Rose, 2009

Nguyen and Rose, 2009

Disclosure: To show vulnerability by sharing personal and/or business confidential information [14] (4 articles)

To give all information

Howorth and Moro, 2012

- She is happy to be transparent with the bank manager

To regularly communicate with the partner during the implementation of the contracts on business information and practices

Nguyen and Rose, 2009

To show vulnerability by sharing confidential information

Maxwell and Lévesque, 2014

To share private information

Jonsson, 2015 [69]

- To provide to partners some of our own personal information

(e.g., background, personal life)

Nguyen and Rose, 2009

Explanation: To explain details and consequence of information provided (1 article) Maxwell and Lévesque, 2014 [14]

Loyalty: To have motives to protect and make the target person look good; altruism and demotivation to lie; willingness to give support ... [4] [44] (8 articles)

To accept her deferential position and engage in appeasement behavior

To trade favors

To be willing to cooperate

- To support goodwill of cooperation

- To explicitly show interest in long term of it

- She shows her commitment by initiating different forms of cooperation
Doern and Goss, 2012 [74]

Bowey and Easton, 2007

Bowey and Easton, 2007

Curtis et al., 2010

Nguyen and Rose, 2009

Doern and Goss, 2012 


\section{Continued}

To make the actors look good

- To give (customer) attention

- To start conversations (with costumer)

Altinay et al., 2014

To help (customer) and try to solve (partners) personal and business problem

Bowey and Easton, 2007;

(e.g., regarding to the contract, like technical help and advanced payment)

Nguyen and Rose, 2009;

Altinay et al., 2014

To not take advantage of (venture capital) even if the opportunity arose

De Clercq and Sapienza, 2006;

Presutti et al., 2011

To provide guarantees for payment and delivery

Welter et al., 2004 [75]

Motives: It consider intentions, positive attitudes, and to want to do good and exhibit concern about well-being of actors [14], taking good actions. In definitely, doing well by doing good (19 articles)

\section{To develop good actions}

- To be generous

To appropriately give this contact person (partner) some gifts

To sharing and offering more than enough

- To take account the actors' interest

To adapt her interests to fit those of commercial partners

To get that they (bank managers) feel of us

To hint themselves in the land that they (entrepreneur team's members) can be part of this

To take decisions in the best interests of all shareholders

- To treat them as "people" not as customer

To provide an important requirement in dealing

To value them (costumers) with their characters and personalities

To treat well clients

To make the client feel well

- To take care the stakeholders

To exhibit concern about well-being of others

To devote genuine care

She always knows what will suit me (customer)

To demonstrate her desire to do good to others

To pay attention to the needs of the employees

- To be a good person

To grant a deferment of payment to its customer without problem

To be good girl

- To send the products to the customer before receiving the entire payment

- To process the customer's order without receiving a formal order

To have a set of intentions, positive attitudes and courtesy

- To signal conscientiousness

Moss et al., 2015
Nguyen and Rose, 2009

Altinay et al., 2014

Howorth and Moro, 2012

Sengupta, 2011

Discua et al., 2013

Kelly and Hay, 2003

Sengupta, 2001

Altinay et al., 2014

Lopes et al., 2009

Maxwell and Lévesque, 2014

Bowey and Easton, 2007; Bergh et al., 2011

Jack and Anderson, 2002

Howorth and Moro, 2006

Howorth and Moro, 2012

Presutti et al., 2011

Doern and Goss, 2012

Presutti et al., 2011

- To show courage 


\section{Continued}

- To display empathy

- To signal warmth

- To be charismatic

- To give to know her personality

- To respect third parties (e.g., bankers, suppliers, customers)

- To work hard and long hours, being an hardworking person

- To portray a positive and humble person

She doesn't tend to get too mad about things

She doesn't get too angry

She tends to be fairly enthusiastic most of the time

She doesn't push that she's a boss in people's faces

She knows she can afford luxurious things, but she lives very, very meekly

- To be merciful in business (as reverse of ruthless).

- To meet the customer before starting the business

- To develop a compassionate enterprise

- How people (society) identified with this story but also how they (society) understand the story

Openness in: To be open to new ideas or new ways of doing things [14] (4 articles)

To ask about it straightaway when she sees or hears something strange in a meeting

To be open to new ideas or new ways of doing things

To learn about the contact person (partners). For example, background, habits, etc.

To be a good listener

Openness out: To communicate ideas freely [44] (7 articles)

To carry out a direct and forthright communication

To be openness

- To tell him (venture capital) something because she knows it herself

- To present herself in an open way

- To openly discuss problems

- To be open in disclosing all relevant information to investors

To be able to discuss the technology, the market, complementary partners in industry, the trading advantages, and the competitors.

To have to say what she thinks
Payne et al., 2009

Schwarzkopf et al., 2010; Sengupta, 2011

Bowey and Easton, 2007; Payne et al., 2009

Jack and Anderson, 2002; Holt and

Macpherson, 2010

Holt and Macpherson, 2010

Discua et al., 2013

Presutti et al., 2011

Sarpong and Davies, 2014 [76]

Batterink et al., 2010

Maxwell and Lévesque, 2014

Nguyen and Rose, 2009

Schwarzkopf et al., 2010

Amatucci and Sohl, 2004; Bowey and Easton, 2007

Amatucci and Sohl, 2004; Scarbrough et al., 2013

Weber and Weber, 2011 [77]

Batterink et al., 2010

Kelly and Hay, 2003; Gordon and Jack, 2010 [78]

Weber and Weber, 2011

Batterink et al., 2010

Receptivity: To be mentally open and receptive in order to give and accept ideas, showing accessibility, willingness to accept others' influence (e.g., by being "coachable") and change [14] [44] (5 articles)

To establish a dialogue

To develop detailed discussion
Bergh et al., 2011

Bergh et al., 2011

- According to norms and rules in the beginning

- Based on what she expected 


\section{Continued}

To be open towards each other

To maintain open dialogues

- To carry out informal communications to form a comprehensive picture of her

- To bring about a communication that lead to friendship

- To manage to really communicative each other

To disagree and agree on what is really important

To respect the wisdom of the entrepreneurs' team member

To demonstrate "coach ability" and willingness to change

Reliance: To show willingness to be vulnerable through delegation of tasks [14] (4 articles)

To show willingness to be vulnerable through delegation of tasks

To know aspects of the other party, such as reliance

To be able to be trusted at all times

Kinship *: Kinship, strong ties, friendship, and closeness ... (16 articles)

To make her acquaintance

- If the bank manager moves to another bank, they will change the bank accordingly: "he knows me very well ..."

- People know her

- She has to make their acquaintance ... It's better to be friends

- To be good acquaintances with all people around her

To keep deeply embedded relations

- To avoid to create procedures and forms to manage the relationships

- To have personal links

- To attend their important personal life events (e.g., wedding or funeral of their family's member)

To have good relations

To expose family atmosphere

- To make customers feel at home

To be friends

The longevity of the relationships with those known for longer timescales

To demonstrate friendship

- To invite customer to socialize

- To invite customer to come and have a chat

- To frequently provide more general conversations

To use of family and friend ties

- To be embedded within the local context through family ties Her family was unfamiliar with the fashion industry but had extensive business knowledge, experience and acumen, were well regarded within the local community and provided both financial and moral support

- The customer is a relative of her/of someone who works in the firm
Batterink et al., 2010

Bergh et al., 2011

Weber and Weber, 2011

Discua et al., 2013

Discua et al., 2013

Maxwell and Lévesque, 2014

Bowey and Easton, 2007; Maxwell and Lévesque, 2014

Sigfusson and Harris, 2012 [79]

De Clercq and Sapienza, 2006

Howorth and Moro, 2006

Jack and Anderson, 2002

Doern and Goss, 2012

Drnovsek et al., 2008 [80]

Curtis et al., 2010

Curtis et al., 2010

Howorth and Moro, 2006

Nguyen and Rose, 2009

Curtis et al., 2010

Altinay et al., 2014

Doern and Goss, 2012; Welter, et al., 2004

Butler et al., 2007

Butler et al., 2007; Altinay et al., 2014

Amatucci and Sohl, 2004; Sigfusson and Harris, 2012 [79]; Discua et al., 2013

Jack and Anderson, 2002

Presutti et al., 2011 


\section{Continued}

To develop strong ties

- Contractual relationships and enforcement are unnecessary

- Intensity of cooperation

- Direct and close relationship

- Frequency of a relationship
Drnovsek et al., 2008 [80]; Presutti et al., 2011

Drnovsek et al., 2008

Drnovsek et al., 2008; Van Gelderen, 2010; Ren et al., 2014 [81] Sigfusson and Harris, 2012

Howorth and Moro, 2006 [13]; Van Gelderen, 2010; Ren et al., 2014

Table 5. Integrity.

$\begin{array}{lll}\begin{array}{l}\text { Trustworthiness } \\ \text { antecedent }\end{array} & \text { Empirical findings } & \text { Authors }\end{array}$

Alignment: Adherence and acceptability of a set of principles, compatibility of beliefs and values (value congruence), and shared values and/or objectives, belong to a group and informal agreements [14] (27 articles)

To adopt informal agreements

- To adherence to informal codes of conduct

Welter and Kautonen, 2005

- To abidance by initially verbal agreement

Weber and Weber, 2011

- To develop transaction with the customer based on usual procedures without formal agreements

Presutti et al., 2011

- To keep informal agreements strict

Jansson, 2011

- To carry out an informal social contract

Bergh et al., 2011

To adherence to formal codes of conduct

Welter and Kautonen, 2005

To meet established incubator's tenant acceptance criteria (by the incubators' established tenant acceptance criteria)

Totterman and Sten, 2005

Common goals and shared value (actions confirm shared values and/or objectives)

- To possess common culture

To be involved in religious activities

To share cultural attributes (e.g. attitude towards education)

Jenssen and Kristiansen, 2004

Being part of an ethnic minority group and sharing a common ethnicity

To keep close cultural ties

To possess similar language

To share common religion

Altinay, 2008

Altinay et al., 2014

Altinay, 2008; Nwankwo and Gbadamosi, 2013 [82]; Altinay et al., 2014; Phillips et al., 2013 [83]

Mobility: It refers to attitudes and habits in geographical travelling where the sense of mobility is part of a group's To share cultural collective subjectivity qualities

Group cohesion: It means ethnic groups and religious sects have strong bonding qualities, moral conformity and ritual practices..

Jenssen and Kristiansen, 2004

- To have demographic tiles 


\section{Continued}

Age

Gender

Race

- To share values

To have similar attitude to work

- To possess geographic tiles (tiles related to natural or man-made features that can shape identities including locale, region, or country)

To share nationality

To have localization and community embeddedness

To share be minority in a foreign country, the distinctiveness of her country of origin from the host country acted as a point of co-identification To be from a similar region or country with similar traditions and history allowed stronger emotional ties in business transactions

- To pursue common objectives, goals and interests

- To hold the same expectations

If you (actor) get to the point where you and she have a shared vision about how the future could roll out, then you've got a couple of options ...
Rhee and White, 2007; Altinay et al., 2014

Amatucci and Sohl, 2004; Altinay et al., 2014

Altinay et al., 2014

Howorth and Moro, 2006; Weber and Weber, 2011; Maxwell and Lévesque, 2014

Discua et al., 2013

Phillips et al., 2013 [83]

Altinay et al., 2014

Howorth and Moro, 2006; Presutti et al., 2011; Schwarzkopf et al., 2010; Bergh et al., 2011; Weber and Weber, 2011;

Discua et al., 2013; Scarbrough et al., 2013; Maxwell and Lévesque, 2014

Scarbrough et al., 2013

- To share cognitive attributes, being it an individual's system of meaning, attitudes, beliefs and identity Common attitudes

Common beliefs

Common knowledge

Common value

- To get congruence of values between actors and her

- To inform about cognitive aspects (e.g. values)

- To share norm

- To meet principle compatibility

- To show homophily through similar characteristics

To display personal affinity

To have common backgrounds

To have social similarities

Howorth and Moro, 2006; Jonsson, 2015

Howorth and Moro, 2006; Schwarzkopf et al., 2010; Jonsson 2015

Howorth and Moro, 2006; Bowey and Easton, 2007

Sigfusson and Harris, 2012

Weber and Weber 2011

Bergh et al., 2011

Gordon and Jack, 2010;

Bowey and Easton, 2007

Jack et al., 2008

Schwarzkopf et al., 2010

Bergh et al., 2011

To show good gut feeling a positive first impression-emotional connectivity There are people (she) to whom you (venture capital) can connect; there's common ground

Weber and Weber, 2011 


\section{Continued}

To share common history

To be subjected to same pressures

To share sense of trauma

To share experience of emigration

- To get mutual understanding

A strong reciprocal understanding in terms of wants, values, and standards of behavior

- To work in the same direction

"Understood we're all in the same boat and we all want to grow and develop"

To work together
Weber and Weber, 2011

Gordon and Jack, 2010

Phillips et al., 2013

Howorth and Moro, 2006

Weber and Weber, 2011

Gordon and Jack, 2010

Schwarzkopf et al., 2010; Discua et al., 2013

Membership* (To belong a group with particular characteristics that other people could identify you as part of it)

- To be communicated symbolically to other organizations

Curtis et al., 2010

- To be associate with local mentor who was well known and highly respected Local mentor took her under his wing and encouraged people to contact her

- To pertain to a network created by a leader in local initiative

Jack and Anderson, 2002

Welter et al., 2008

- To be membership in a training program

Gordon and Jack, 2010

- To be member of a specific association

Altinay et al., 2014

To belong to a guild association

To be a member of the board of a very important association

Welter and Kautonen, 2005

Howorth and Moro, 2006

Ingstad et al., 2014 [84]

McAdam and Marlow, 2007 [85]

- To belong to an incubator

Some tenants are better suited than others to become members of an incubator community. In this line, tenants seek belonging and a spirit of comradeship from other tenants. Tenants seek identification from being a member of a

Totterman and Sten, 2005 community

To be mixed up in the atmosphere within the start-up incubators, being the atmosphere within the start-up incubators such as Triple $\mathrm{Z}$ might have helped Welter et al., 2008 to facilitate trust

- To establish relation with incubator's manager

It is interesting to observe that all incubator managers involve themselves in Totterman and Sten, 2005 tenants' stakeholder negotiations

Consistency: The extent to which her actions are congruent with his or her words, such as promise fulfillment and reliability [14] [44] (14 articles)

To be consistent in her decisions and behavior

De Clercq and Sapienza, 2006; Howorth and Moro, 2012

Promise fulfillment

- To carry out the promise

To keep her word

Batterink et al., 2010

To display behaviors that confirm previous promises

Maxwell and Lévesque, 2014

Jean and Tan, 2001; Jones and Rowley, 2011;

Altinay et al., 2014

De Clercq and Sapienza, 2006; Bergh et al.,

To be truly sincere in her promises 


\section{Continued}

To deliver on promises

- To involve in a good undertaking
Kelly and Hay, 2003; Bowey and Easton, 2007

Curtis et al., 2010

Reliability (To follow up on any appointment and commitment made and to show adequate judgment to act in encountered situation)

- To develop actions

More actions and less chatting

- To establish trustful and authentic relationships

- To create a common investment (degree of commitment)

- To do her best to avoid any default
Curtis et al., 2010

Lopes et al., 2009

Presutti et al., 2011

Howorth and Moro, 2012

Discreetness: To avoid to chat and keep confidence regarding the secrets that each actor tells her [4] [44] (3 articles)

To maintain confidentiality

- To have closure of the social structure (e.g. confidentiality)

Gordon and Jack, 2010

- To follow confidentiality rule

Bergh et al., 2011

To keep secrets

Jack et al., 2008

Fairness: To treat people equal and strong sense of justice [4] [44] (6 articles)

To follow fair trade practices

Altinay et al., 2014

To share incentive of equity participation

Schwarzkopf et al., 2010

To treat people fairly and justly

De Clercq and Sapienza, 2006

To know that their (entrepreneur team's member) decision will be based on fair

To be fair about what she does herself

Discua et al., 2013

Batterink et al., 2010; Bergh et al., 2011

Honesty: To be sincere and truthfulness [4] [44] (8 articles)

To be honest:

- in his business relationship

- in negotiations with commercial partners

To report financial data without manipulation

To know that her decision will be based on truth

To be legal

To show credibility

- To display credibility through a formal system and quantified data

De Clercq and Sapienza, 2006; Jack et al., 2008; Batterink et al., 2010; Sigfusson and Harris, 2012; Discua et al., 2013

Howorth and Moro, 2012

Howorth and Moro, 2012

De Clercq and Sapienza, 2006; Discua et al., 2013

Discua et al., 2013

Jones and Rowley, 2011

Holt and Macpherson, 2010

Moral character: The intrinsic moral norms a trustee guards her actions with [4] [44] (6 articles)

To follow ethical principles

- Should not cheat (on customer)

Howorth and Moro, 2006

Altinay et al., 2014

To highlight the importance of community involvement, such as charity work, schools, local politics ...

- To be a member of the local volunteering fire brigade or volunteering emergency service

- To be involved and/or supportive of church activity, being a member of the city council, etc. 


\section{Continued}

- To contribute to business benefits the local community

- To start off slowly with the voluntary community center.

She did a few jobs for Home Star (a leading family support charity)

- To remain informal "contratsmoraux"

She has not signed a contract, but there was even such situation that I was entrusted this year with organizing such "Day of Solidarity" with mentally sick person

To do what is right

To know that be a man God and not compromise faith or family
Jack and Anderson, 2002

Curtis et al., 2010

Curtis et al., 2010

De Clercq and Sapienza, 2006

Discua et al., 2013

Regarding ability, Table 3 shows 107 empirical findings, gathered by 30 articles. According to the evidences revised, functional/specific competence is the antecedent most proved. Numerous studies reported the significant effect of possessing competence, having knowledge, and displaying skills. Also, there are several empirical findings supporting the importance of showing experience as a relevant aspect to perceive entrepreneur's ability. Although a little less reported, previous literature also shows business sense as key antecedent of the entrepreneur's ability. In this sense, "to have widow about how a business works" is signaled in different articles by demonstrating professionalism, understanding on everything hang together, being able to develop a business plan, or managing the needed resources and changing conditions of market, among others. Likewise, entrepreneur interpersonal competence is slightly evidenced as an ability antecedent, being able to develop gestural language or a process of convincement, among others. Finally, an article found that to make accurate and objective decisions by the entrepreneur contributed to her ability valuation.

We have found 145 empirical findings, gathered by 39 articles, related with an inclusive trustworthiness antecedent of benevolence, as Table 4 shows. In this case, several studies reported significant effect of "doing well by doing good" on benevolence. Entrepreneur's motive, as the most frequently revealed antecedent, has been deduced by different stakeholders from developing good actions, and having a set of intentions, positive attitudes and courtesy in different ways. Likewise, there is large evidence about how accuracy is a key antecedent of benevolence. In this regard, exchanging high-quality information, and providing accurate, fine-grained, completeness and adequate communication have been perceived as a signal of benevolence in some empirical studies. Also such a lot articles show the importance of trying to prove loyalty to be perceived as trustworthy, highlighting aspects as providing guarantees for payment and delivery and not taking advantage of even if the opportunity arose. With some less frequency, empirical findings corroborate the importance of demonstrate availability or disclosure as antecedent of benevolence. The finding about availability remarks the relevance of promoting proximity whereas disclosure has been showed by sharing personal and confidential information among others. Other key aspect signaled by previous studies with abundant findings is to exchange 
ideas. This is regarding to openness in, openness out and receptivity, such being open to new ideas, communicating them or both. Although reliance is showed only in three articles, they offer significant effect of the willingness to be vulnerable through delegation of task on the generation of trust. To end with the antecedent proposed by previous literature, only an article details how explaining details and consequence of information provided by the entrepreneur contributed to her benevolence valuation. Complementing former list of benevolence antecedents, identified in prior studies, we found that other empirical findings, such as strong tie, friendship and close relation developed by entrepreneurs that created trust, could be associated around the concept of kinship emerging as a relevant in this entrepreneurial context. This new trustworthiness antecedent, evidenced in 16 articles, underlines keeping deeply embedded relations, making her acquaintance, using of family and friend ties, or developing strong ties.

Table 5 shows integrity as the next factor that subsumes alignment, consistency, discreetness, fairness, honesty and moral character, with 133 empirical findings, gathered by 36 articles. Related with this entrepreneur's trustworthiness factor, the numerous articles and the difference with the evidences of the others antecedents confirm that alignment is the most prominent antecedent. Findings show that adopting informal agreements, common goals and shared value, value congruence, and membership act as cues of alignment to be perceived. Regarding the last aspect, membership was not gathered into our coding guide and because its meaning is to belong a group with particular characteristics that other people could identify you as part of it, it was added into alignment. Also, our revision shows consistency, signaling by promise fulfillment or reliability, is a recurrent antecedent assessed by the stakeholders to deduce entrepreneur benevolence. Finally, although with minor evidences compared with respect the two former, an important number of articles support the rest of antecedents previously identified in the literature. These articles prove that maintained confidentiality; to be honest, following ethical principles and to show credibility make the entrepreneur trustworthy.

In this way, our results confirm the model proposed by Mayer et al., 1995, enriching it with a list of behaviors, attitudes and characteristics that illustrate how the entrepreneur is perceived as trustworthy in the early stages of her venture. Additionally, our review comes out other elements that influence in the entrepreneur stakeholders' valuation and their trust on her that we were not able to locate into the ABI model. According to Schoorman et al., 2007 suggestion, we use our finding to expand the model of Mayer et al., 1995 including a new factor of perceived trustworthiness, entrepreneur social interactions. As Table 6 exhibits, this factor is supported by 35 empirical findings, gathered by 17 articles. In our review, some empirical findings noticed that most entrepreneurs and stakeholders spent considerable time, engaged in informal get-togethers and informal talks and meetings, and these are key for trust building. In the entrepreneurial context, social interactions help to build the foundation for the development of 
trust, as an important aspect to understand why some entrepreneurs are more trusted than others. In fact, several studies evidence that when stakeholders meet entrepreneur having a good time and knowing each other through informal talks and informal social activities, stakeholders valuate it. Social interactions are entrepreneur's actions valuated by stakeholders that lead her to be more (or less) trusted. Consequently, we propose it as another trustworthy factor, it means that social interactions can be valued as another trustee's attribute by stakeholders to build their trust based on three antecedents, such as informal meeting, networking and network.

Table 6. Social interaction

Trustworth. antecedent

Empirical findings

Authors

Informal meeting: A planned occasion when people meet in order to have a good time together and better get to know each other in an informal environment ( 8 articles)

To involve informal social contact get-together with them (partners) on some holiday Nguyen and Rose, 2009; Bergh et al., occasions 2011

To have fun together and involve personal matters

Bergh et al., 2011

To carry out informal talks

Bowey and Easton, 2007; Bergh et al., 2011

To define the purchase order in a nonworking environment

Presutti et al., 2011

To set up informal social activities

Bowey and Easton, 2007; Gordon and Jack, 2010; Bergh et al., 2011

To create informal relationships

Presutti et al., 2011

To put into informal procedures in the transaction with the customer

Presutti et al., 2011

To realize social relationship

Cruickshank and Rolland, 2006

To engage in informal social activity with the investor (e.g., playing golf, going to a

Bowey and Easton, 2007; restaurant)

Freiburg and Grichnik, 2012 [87]

To initiate close and informal relations

Jansson, 2011

Networking: Activities of sharing information and services among entrepreneur and actors around her (7 articles)

To carry out meetings and social events

Bowey and Easton, 2007; Batterink et al., 2010; Bergh et al., 2011; Moro et al.,

- To realize partners physically meet 2014; Batterink et al., 2010; Curtis et al., 2010

To do communication networking

Cruickshank and Rolland, 2006

To organize events where people meet from previous activities

Van Gelderen 2010

Network: To interact with actors to exchange information, have a good relationship and develop professional or social contact (9 articles)

To establish personal contacts

- To carry out personal networks

- She had this sort of conversation with a few people, and eventually she made contact with a woman through a contact she knew through a charity She's a chair of
Lopes et al., 2009; Sengupta, 2011

Welter et al., 2004

Curtis et al., 2010 


\section{Continued}

- To be proactive through seeking information about inter-organizational and intra-organizational networks of weak ties (e.g., e-mailing colleagues or external contacts to see whether they see potential in an idea or partner)

- To develop a structural dimension patterns of social interaction that allow her to use personal contacts to her advantage

Cruickshank and Rolland, 2006

To rely on informal networks (e.g., friends)

- To enforce the contracts with her partners

- To demonstrate your reputation to this partner

Nguyen and Rose, 2009

- To learn about her partners

To use online networks

- She met him (partner) at the trade show and they exchanged emails. They connected on LinkedIn and after 3 years of silence he contacted her and they realized they could do business together. They realized after being connected on Sigfusson and Harris, 2012 LinkedIn for some time but never met, that they both had same contacts in New York, hooked up and did a project with these guys"

To develop different practices based on ICT in order to communicate and interact with partner, such as telephone, e-mail, digital document sharing, video conferencing Batterink et al., 2010 or workshops

Furthermore, the strength or closeness of social relationships as contacts between parties [61] is a mean to positively influence on trustworthiness valuations. According to Ariño et al., 2001 [86], we also propose that entrepreneurs' social interactions help stakeholders to facilitate the identification process and trustworthiness evaluation. Consequently, because entrepreneur's interactions with stakeholders allow professional or social contacts, we depict in our model that it could facilitate not only her trustworthiness valuation but also interact with former ABI factors, as Figure 1 exhibits.

In addition, from the empirical evidence of past research we have detected other elements, such as previous experiences, reputation and/or third parties sources of information, influencing in trust building process. Prior trust research reveals that trust, as an outcome of initial cognitive cues and first impression, may also stem from third-party referrals and second-hand information about the trustee [88]. This idea could consider what other factors could influence the weighting of any one of the hypothesized antecedents on trust at early stages of a new venture. As Table 7 shows, prior experiences play an important role in terms of sharing pre-established personal relationships, having knowledge of beforehand by pre-established networks and living specific situations together. Previous personal relationships are prominent, emphasizing that they knew each other from earlier relationships, which significantly influences stakeholders' entrepreneur valuation.

Likewise, Table 8 exhibits that to have a good reputation through being subject to formal mechanism, displaying reputation of her customers or suppliers, setting external validation, using the country brand and image of the profession is significant in establishing a trusting relationship. In new entrepreneur-stakeholders relationships, third parties is a source of information used by stakeholders who 
want to know about the entrepreneur and which affect the development of trust on her. In particular, gossips, recommendations, introduction and endorsement by other people who know her could affect the entrepreneur's valuation. All together, these empirical findings suggest the possibility that these elements, prior experiences and reputation/third parties moderate stakeholders' valuation about entrepreneur trustworthiness.

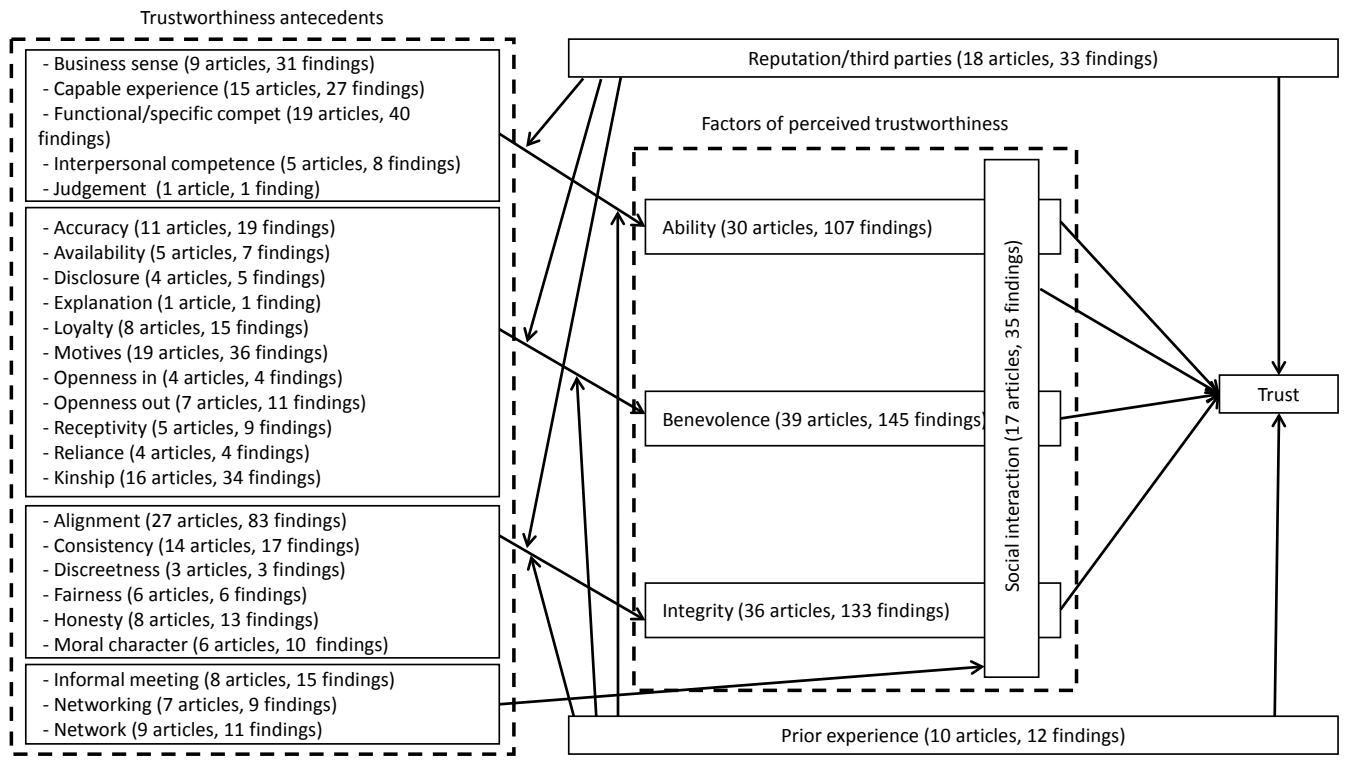

Figure 1. Conceptual model.

Table 7. Prior experience.

\begin{tabular}{ll}
\hline Empirical findings & Authors \\
\hline To share experience in terms of pre-established personal relationships & Jonsson, 2015 \\
$\bullet$ I (venture capital) was happy that I knew her from an earlier life, something that greatly & \\
simplified the personal side of things & Weber and Weber, 20 \\
$\bullet$ I (venture capital) have known her for years (from boarding school) & Discua et al., 2013 \\
$\bullet$ Know each other & Welter et al., 2004
\end{tabular}

To have knowledge of beforehand by pre-established networks

- There was still greater trust in those networks established prior to entering the incubator

McAdam and Marlow, 2007 [85]

- Community embeddedness also creates substantial trust “...”. She had been a private

entrepreneur before venturing into social entrepreneurship

Curtis et al., 2010

To live specific situation together in terms of prior dealings and experiences

- Information from past dealings

Sørheim, 2005 [89]

- Mutual experiences gained in dealing with each other

Welter et al., 2008

- Experience of working together (with venture capital)

Schwarzkopf et al., 2010

- To work with someone for a long term

Discua et al., 2013

- The investor had already previously invested in a fund, in which she was involved

- The investor had a professional relationship with her

Freiburg and Grichnik, 2012 [87] 
Table 8. Reputation/third parties.

$\begin{array}{lll}\begin{array}{l}\text { Information } \\ \text { sources }\end{array} & \text { Empirical findings } & \text { Authors }\end{array}$

Reputation (is the result of past actions and shapes our anticipation of behavior [13] [90] (16 articles)

To have a good reputation

To be subject to formal mechanism by going public (initial public offer)

To develop a tie with institutions that possess high status

To receive support from the public sector

- Actors (public sector) believed in the project

To get public funding

- Small amounts of money are provided, but these small amounts are important because it proves somebody trusted her.

To display reputation of her customer/supplier

To use country brand

- She mentions that have utilized the country brand to create positive associations with trustworthiness

To show the image of the profession

To demonstrate standards set by professional associations

To get external validation

- To verify her credentials by other ties (e.g., due diligence on a management team or company, verification of specific competencies by involving another expert with Scarbrough et al., 2013 domain knowledge)

Third parties (information that is proved by a person who know the entrepreneur) (10 articles)

Gossip about her

- One can access stories about her trustworthiness through third parties

Introduction and endorsement by third party

- Informal third parties (in social networks) can endorse the relationship and signal similar values and beliefs

- To convert strangers into friends through common thirds parties to bridge

- Venture Capitals acquired information from third parties, either whom they (venture capital) knew or from her reputation in a relatively small community

- Introductions from other trusted (strong) ties in an actor's network (e.g., referrals from friends and family)

Recommendations developed by other people who know her

- To make the approach through a referral source that knows her and whose opinions and judgments are trusted by business angels

- I (bank manager) had heard and gain information about her from other customer

- I (bank manager) gain information about your client (she) from other customers

- Good, relevant references, and word-of-mouth recommendations
Jean and Tan, 2001; Kelly and Hay, 2003; Welter and Kautonen, 2005; Howorth and Moro, 2006; Holt and Macpherson, 2010; Schwarzkopf et al., 2010; Sengupta, 2011; Discua et al., 2013; Howorth and Moro, 2012; Sigfusson and Harris, 2012

Ravasi and Marchisio, 2003 [91]

Scarbrough et al., 2013

Curtis et al., 2010

Curtis et al., 2010

Welter et al., 2004

Lehto, 2015

Welter and Kautonen, 2005

Welter and Kautonen, 2005

Lopes et al., 2009

Bowey and Easton, 2007

Howorth and Moro, 2006

Nguyen and Rose, 2009

Schwarzkopf et al., 2010

Scarbrough et al., 2013

Welter et al., 2004

Kelly and Hay, 2003

Howorth and Moro, 2012

Holt and Macpherson, 2010; Lehto, 2015 
Our literature review and the previous analysis of each factor and antecedent give a unique insight into the current status regarding research on trust between entrepreneur and different stakeholders. According to former findings, Figure 1 displays four factors, such as ability, benevolence, integrity and social interaction (ABISI), joined a set of trustworthiness antecedents, together with two moderator elements found. The trustor's propensity to trust is not considered, because it is identified as a trustor's characteristic, relatively stable, and due to it is not possible to manage by the trustee.

From our previous analysis, we have found that prior research in entrepreneurship has studied empirically, with different intensity, this topic regarding different kind of stakeholders. In fact, the ecosystem or network (18 articles), partners (12 articles), investors (11 articles), customers (11 articles) are the most studied trustors. Whereas the interest for other such bank (5 articles), or other entrepreneurs ( 5 articles) has been minor, or relatively scarce as the case of public sector ( 2 articles) and employees ( 1 article). To determine whether there is common trustworthiness schema for all them, we develop a comparison across stakeholders. In terms of appearance or frequency, our analysis shows that some antecedents are common for most of them affecting each stakeholder's valuation, some are more prominent than others to aspecific stakeholder or simply do not appears to influence in their valuation, when we take into consideration the factors by stakeholders groups. As Table 9 gathers, functional/specific competence and capable experience appear as the prominent antecedents for ability valuation for practically all stakeholders. Similarly, motives and kinship are the flagrant antecedents for the benevolence assessment. Likewise, most of the stakeholders take into consideration alignment and consistency to assess the entrepreneur integrity and finally and interestingly, most stakeholder bases entrepreneur's trust on social interactions, but there is not a common antecedent for all of them(see Table 9).

If this table of frecuency (see Table 9) is analysed by colums, we can obtain an especific ABISI model and identify key antecedents for each stakeholder, allowing us to develop customized models. Thus according with the empirical findings obtained by previous literature:

- Integrity and concretelly his antecedent, allignment, is clearly the aspect more prominent to be trusted by the entrepreneur's network or ecosystem. Aditionally her ecosystem prominently evalues her ability considering her functional and specific competences, and her benevolence by her accuracy. There is not empirical findings about other relevant antecedents, e.g., business sense.

- In the case of customers, the prominnecy of the three factors of Mayer et al., 1995 is balanced. Customers asses ability also mainly by functional and specific competences, benevolence has been evaluated primarily by motives and integrity taken into consideration alignment and consitency. Other relevant antecedents, e.g., accuracy, openness (in, out and receptivity) and networking, do not present empirical evidence. 
- Investors, that gather stackeholders like business angels, venture capital, institutional investors or even microlenders, have trusted in stakholders mainly judging her capable experience, functional competences, accuracy, motives, openness out, alignment and consitency. Interpersonal competence does not have founded as antecedent.

Table 9. Antecedents' appearance and frequency by stakeholder type.

\begin{tabular}{|c|c|c|c|c|c|c|c|c|c|c|}
\hline Factor & Antecedents & Ecosystem & Customer & Investor & Partner & Bank & $\begin{array}{l}\text { Other } \\
\text { entrep. }\end{array}$ & Employee & $\begin{array}{l}\text { Public } \\
\text { sector }\end{array}$ & Total \\
\hline \multicolumn{11}{|l|}{ Ability } \\
\hline & Business sense & - & 1 & 3 & 2 & 2 & - & - & 1 & 10 \\
\hline & Capable experience & 2 & 3 & 4 & 3 & 1 & 1 & - & 1 & 14 \\
\hline & Functional/specific comp. & 4 & 5 & 5 & 2 & 2 & 1 & - & 1 & 20 \\
\hline & Interpersonal competence & 1 & 1 & - & - & - & 1 & 1 & 1 & 5 \\
\hline & Judgment & - & - & 1 & - & - & - & - & - & 1 \\
\hline \multicolumn{11}{|c|}{ Benevolence } \\
\hline & Accuracy & 4 & - & 4 & 2 & 1 & - & - & - & 11 \\
\hline & Availability & - & 2 & - & 2 & - & 1 & - & - & 5 \\
\hline & Disclosure & 1 & - & 1 & 1 & 1 & - & - & - & 4 \\
\hline & Explanation & - & - & 1 & - & - & - & - & - & 1 \\
\hline & Loyalty & 1 & 2 & 1 & 2 & - & - & - & 2 & 8 \\
\hline & $\underline{\text { Motives }}$ & 2 & 6 & 6 & 2 & 3 & 1 & - & 1 & 21 \\
\hline & Openness in & - & - & 2 & 2 & - & - & - & - & 4 \\
\hline & Openness out & 1 & - & 4 & 1 & - & 1 & - & - & 7 \\
\hline & Receptivity & - & - & 2 & 2 & - & 1 & - & - & 5 \\
\hline & Reliance & 1 & - & 2 & 1 & - & - & - & - & 4 \\
\hline & Kinship & 1 & 3 & 1 & 8 & 1 & - & - & 2 & 16 \\
\hline \multicolumn{11}{|c|}{ Integrity } \\
\hline & Alignment & 9 & 5 & 5 & 6 & 1 & 5 & - & 1 & 32 \\
\hline & $\underline{\text { Consistency }}$ & 3 & 4 & 4 & 2 & 1 & 1 & - & 1 & 16 \\
\hline & Discreetness & 1 & - & - & - & - & 2 & - & - & 3 \\
\hline & Fairness & - & 1 & 2 & 2 & - & 1 & - & - & 6 \\
\hline & Honesty & 1 & 2 & 1 & 3 & 1 & - & - & - & 8 \\
\hline & Moral character & - & 2 & 1 & 1 & 1 & - & - & 1 & 6 \\
\hline \multicolumn{11}{|c|}{ Social interaction } \\
\hline & Informal meeting & 2 & 2 & 1 & 1 & - & 2 & - & - & 8 \\
\hline & Networking & 2 & - & - & 2 & 1 & 1 & - & 1 & 7 \\
\hline & Network & 1 & 1 & 2 & 4 & - & - & - & 1 & 9 \\
\hline
\end{tabular}

All cells with the border are the most prominent. 
- In her relations with partners, clearily kinship, alignment, network act as prominent antecedents. Similarly, interpersonal competence does not have founded.

- Although the empirical findings are lower, our analysis highlights business sense and functional competence as antecedents for ability, and motives for benevolence in her relationships with banks. In this case, aspects as interpersonal competence, loyalty, openness (in, out, and receptivity), informal meetings and network appear as no relevant.

- Similarly, regarding her relations with other entrepreneurs, alignment presents its importance as antecedent.

- With only an article focused on it, interpersonal competence appears as a relevant antecedent regarding her relations with employees.

- Finally, kinship and loyalty are founded as antecedents regarding the public sector. Although in the same way of the former, this only represents the finding of one article.

\section{Conclusions}

This paper proposes a further understanding of how the entrepreneur can build intentionally stakeholders' trust. Based on an extensive empirical literature review, some answers were found to the following questions 1) what are the entrepreneur's factors of perceived trustworthiness? 2) What are specific entrepreneur's characteristics, attitudes and behaviors that improve her stakeholders' valuation? And 3) is there differences across diverse stakeholders? In this way our proposed model updates, adapts and details the ABI schema to the entrepreneurial setting.

Lewis and Weigert, 1985 suggested that trust is based on "good reasons' constituting evidence of trustworthiness" and Mayer et al., 1995 clear those "good reasons" in terms of ability, benevolence, and integrity. Our analysis of previous empirical evidence supports the importance of all these three trustworthiness factors for entrepreneur to build stakeholders trust, but also it evidences the relevance of social interactions. In this regard, our model extends ABI model to include it as an entrepreneur specific trustworthiness factor developing a twofold role, and it will be considered an important factor in the assessment of trustworthiness by the stakeholders and it will affect assessments of other trustworthiness.

An interesting aspect emerges in our study, is that a variety of information has a strong impact on the assessment of trustworthiness. In particular, multiple sources of information lead up to this evaluation, including sources such as reputation/third parties and prior experiences that were deduced from the empirical articles considered. In addition, our model goes into details drawing antecedents of each trustworthiness factor offering a widen inventory of attitudes, behaviors and characteristics that entrepreneurs could signal to favor their valuations.

Furthermore, advancing on it, our analysis of frequencies offers a picture 
about what aspects should be exhibited to facilitate the formation of each stakeholder's trustworthiness valuation. We detected the potentially bases of trust across different stakeholder groups (e.g. investors, partners, customers, etc.) where each stakeholder through different trustworthiness antecedents perceived the same factors. Prior research analyzed on trust in an entrepreneurial context, however, has not distinguished between the potentially varying bases of trust across stakeholders [52].

In this way, our model offers practical implications. The proposed model can be used as a reference for entrepreneurs confronting with the challenge of creating an identity as a trustworthy person across stakeholders groups in a trust requiring situation. Entrepreneurs can see our model and its antecedent inventory as a practical guide to identify cues of how to communicate trustworthiness factors effectively for each stakeholder.

Building on the results and limitations of this study, we discuss specific areas for future research. First of all, the search was restricted to articles published in the period between 2000 and 2015. Further research is needed to cover the period until today. Likewise, the search was limited to the cognitive process, involving signaling and demonstrating trustworthiness factors. However, trusting is a process that but also establishes an emotional connection [92]. The affective approach requires further development with the aim of proving an understanding of the association between affective nature of trust and factors of perceived trustworthiness and their antecedents. Thus, future research could focus on how trust-building models could include both components that affect individual's impression formation and judgments.

Another limitation is that our conceptual model takes the perspective of active entrepreneurs building trust, considering differences from the stakeholders' point of view, trustors. But trust also depends on the trustor's characteristics, and specifically his/her propensity to trust others [13]. Further research could consider this variable searching for communalities among stakeholders. In this regard, because prior research is mainly centered on investors, partners and customers, more research is necessary to better know how other relevant stakeholders (e.g., employees, public sector) build trust.

Similarly, our model is just focus on the trustworthiness antecedents assuming that trust fosters stakeholders' risk taking and has other positives effects on variables such as commitment, learning or collaboration. An interesting avenue for future research would be to test whether these stakeholders' actions will provoke benefits for the entrepreneur, counterbalancing her signaling effort. Furthermore, Colquitt et al., 2007 results suggest that trustworthiness may be important even aside from their trust-fostering role, having unique relationships with behavioral outcomes even when trust was considered simultaneously. From this perspective, we also suggest testing this trustworthiness' dual importance-predicting behaviors through the mechanisms of trust or analysing directly how it leads to behavioral outcomes like risk taking or commitment. 
Finally, this study limits the search to the entrepreneurial literature, perhaps more evidences could be found in other journals, it is an important step to be tested empirically through qualitative and/or qualitative methods. In this line, further steps need to consider the weight of each antecedent, the contextual setting, even how the empirical model will develop from early stages on time across next stages.

\section{Conflicts of Interest}

The authors declare no conflicts of interest regarding the publication of this paper.

\section{References}

[1] Hoang, H. and Antoncic, B. (2003) Network-Based Research in Entrepreneurship: A Critical Review. Journal of Business Venturing, 18, 165-187. https://doi.org/10.1016/S0883-9026(02)00081-2

[2] Cherry, B. (2015) Entrepreneur as Trust-Builder: Interaction Frequency and Relationship Duration as Moderators of the Factors of Perceived Trustworthiness. International Journal of Business and Globalisation, 14, 97-121. https://doi.org/10.1504/IJBG.2015.066098

[3] Pollack, M., Barr, S. and Hanson, S. (2017) New Venture Creation as Establishing Stakeholder Relationships: A Trust-Based Perspective. Journal of Business Venturing Insights, 7, 15-20. https://doi.org/10.1016/j.jbvi.2016.12.003

[4] Mayer, R.C., Davis, J.H. and Schoorman, F.D. (1995) An Integrative Model of Organizational Trust. Academy of Management Review, 20, 709-734. https://doi.org/10.5465/amr.1995.9508080335

[5] Smith, D.A. and Lohrke, F.T. (2008) Entrepreneurial Network Development: Trusting in the Process. Journal of Business Research, 61, 315-322. https://doi.org/10.1016/j.jbusres.2007.06.018

[6] Lewis, J.D. and Weigart, A. (1985) Trust as a Social Reality. Social Forces, 63, 967-985. https://doi.org/10.1093/sf/63.4.967

[7] Moensted, M. (2007) Strategic Networking in Small High Tech Firms. International Entrepreneurship and Management Journal, 3, 15-27.

https://doi.org/10.1007/s11365-006-0019-7

[8] Droege, S.B. and Anderson, J.R. (2003) Trust and Organizational Information Flow. Journal of Business \& Management, 9, 45-59.

[9] Swärd, A. (2016) Trust Processes in Inter-Organizational Relations: The Role of Imprinting. In: Trust, Organizations and Social Interaction. Studying Trust as Process within and between Organizations, Edward Elgar, Cheltenham, 167-186. https://doi.org/10.4337/9781783476206.00019

[10] Colquitt, J.A., Scott, B.A. and LePine, J.A. (2007) Trust, Trustworthiness, and Trust Propensity: A Meta-Analytic Test of Their Unique Relationships with Risk Taking and Job Performance. Journal of Applied Psychology, 92, 909-927. https://doi.org/10.1037/0021-9010.92.4.909

[11] Nguyen, T.V. and Rose, J. (2009) Building Trust-Evidence from Vietnamese Entrepreneurs. Journal of Business Venturing, 24, 165-182.

https://doi.org/10.1016/j.jbusvent.2008.03.004

[12] Jenssen, J.I. and Kristiansen, S. (2004) Sub-Cultures and Entrepreneurship: The 
Value of Social Capital in Tanzanian Business. The Journal of Entrepreneurship, 13, 1-27. https://doi.org/10.1177/097135570401300101

[13] Howorth, C. and Moro, A. (2006) Trust within Entrepreneur Bank Relationships: Insights from Italy. Entrepreneurship Theory and Practice, 30, 495-517. https://doi.org/10.1111/j.1540-6520.2006.00132.x

[14] Maxwell, A.L. and Lévesque, M. (2014) Trustworthiness: A Critical Ingredient for Entrepreneurs Seeking Investors. Entrepreneurship Theory and Practice, 38, 1057-1080. https://doi.org/10.1111/j.1540-6520.2011.00475.x

[15] Discua Cruz, A., Howorth, C. and Hamilton, E. (2013) Intrafamily Entrepreneurship: The Formation and Membership of Family Entrepreneurial Teams. Entrepreneurship Theory and Practice, 37, 17-46. https://doi.org/10.1111/j.1540-6520.2012.00534.x

[16] Neergaard, J.P. and Ulhøi, H. (2006) Government Agency and Trust in the Formation and Transformation of Interorganizational Entrepreneurial Networks. Entrepreneurship Theory and Practice, 30, 519-539. https://doi.org/10.1111/j.1540-6520.2006.00133.x

[17] Welter, F. (2012) All You Need Is Trust? A Critical Review of the Trust and Entrepreneurship Literature. International Small Business Journal, 30, 193-212.

[18] Schoorman, F.D., Mayer, R.C. and Davis, J.H. (2007) An Integrative Model of Organizational Trust: Past, Present and Future. Academy of Management Review, 32, 344-354. https://doi.org/10.5465/amr.2007.24348410

[19] Moran, P., et al. (2014) Reaching and Acquiring Valuable Resources: The Entrepreneur's Use of Brokerage, Cohesion, and Embeddedness. Entrepreneurship Theory and Practice, 40, 49-79. https://doi.org/10.1111/etap.12103

[20] Jack, S., Dodd, S.D. and Anderson, A.R. (2008) Change and the Development of Entrepreneurial Networks over Time: A Processual Perspective. Entrepreneurship \& Regional Development, 20, 125-159. https://doi.org/10.1080/08985620701645027

[21] Freeman, R.E. (1984) Strategic Management: A Stakeholder Approach. Pitman, Boston.

[22] Welter, F. and Kautonen, T. (2005) Trust, Social Networks and Enterprise Development: Exploring Evidence from East and West Germany. International Entrepreneurship and Management Journal, 1, 367-379. https://doi.org/10.1007/s11365-005-2601-9

[23] Tang, J., et al. (2014) Proactiveness, Stakeholder-Firm Power Difference, and Product Safety and Quality of Chinese SMEs. Entrepreneurship Theory and Practice, 38, 1129-1157. https://doi.org/10.1111/etap.12029

[24] Nagy, B.G., Pollack, J.M., Rutherford, M.W. and Lohrke, F.T. (2012) The Influence of Entrepreneurs' Credentials and Impression Management Behaviors on Perceptions of New Venture Legitimacy. Entrepreneurship Theory and Practice, 36, 941-965. https://doi.org/10.1111/j.1540-6520.2012.00539.x

[25] Peiro, J.M., et al. (2015) Trust and Social Capital: Challenges for Studying Their Dynamic Relationship. In: Lyon, M.S.F. and Mollering, G., Eds., Handbook of Research Methods on Trust, Edward Elgar Publishing, Northampton, 86-96. https://doi.org/10.4337/9781782547419.00016

[26] Butler, A., Reed, M. and Le Grice, P. (2007) Vocational Training: Trust, Talk and Knowledge Transfer in Small Businesses. Journal of Small Business and Enterprise Development, 14, 280-293. https://doi.org/10.1108/14626000710746709

[27] Goel, S. and Karri, R. (2006) Entrepreneurs, Effectual Logic, and Over-Trust. En- 
trepreneurship Theory and Practice, 30, 477-493.

https://doi.org/10.1111/j.1540-6520.2006.00131.x

[28] Batterink, M.H., Wubben, E.F.M., Klerkx, L. and Omta, S.W.F. (2010) Orchestrating Innovation Networks: The Case of Innovation Brokers in the Agri-Food Sector. Entrepreneurship \& Regional Development, 22, 47-76. https://doi.org/10.1080/08985620903220512

[29] Welter, F., Trettin, L. and Neumann, U. (2008) Fostering Entrepreneurship in Distressed Urban Neighbourhoods. International Entrepreneurship and Management Journal, 4, 109-128. https://doi.org/10.1007/s11365-007-0069-5

[30] Welter, F. and Smallbone, D. (2006) Exploring the Role of Trust in Entrepreneurial Activity. Entrepreneurship Theory and Practice, 30, 465-475. https://doi.org/10.1111/j.1540-6520.2006.00130.x

[31] Möllering, G. (2013) Trust without Knowledge? Comment on Hardin, Government without Trust. Journal of Trust Research, 3, 53-58. https://doi.org/10.1080/21515581.2013.771504

[32] Nooteboom, B. (2015) Agent-Based Simulation of Trust. In: Handbook of Research Methods on Trust, Edward Elgar Publishing, Northampton, 65-74. https://doi.org/10.4337/9781782547419.00014

[33] Welter, F. and Alex, N. (2015) Researching Trust in Different Cultures. In: Handbook of Research Methods on Trust, Edward Elgar Publishing, Northampton, 75-85. https://doi.org/10.4337/9781782547419.00015

[34] Williams, M. (2007) Building Genuine Trust through Interpersonal Emotion Management: A Threat Regulation Model of Trust and Collaboration across Boundaries. Academy of Management Review, 32, 595-621. https://doi.org/10.5465/amr.2007.24351867

[35] Lewicki, R.J., et al. (2015) Trust Research: Measuring Trust Beliefs and Behaviours. In: Handbook of Research Methods on Trust, Edward Elgar Publishing, Northampton, 46-64. https://doi.org/10.4337/9781782547419.00013

[36] Meyerson, R.M., Weick, D. and Kramer, K.E. (1996) Swift Trust and Temporary Groups. In: Kramer, R.M. and Tyler, T.R., Eds., Trust in Organizations: Frontiers of Theory and Research, Sage, Thousand Oaks, 166-195. https://doi.org/10.4135/9781452243610.n9

[37] Lewicki, B.B. and Bunker, R.J. (1996) Developing and Maintaining Trust in Work Relationships. In: Kramer, R.M. and Tyler, T.R., Eds., Trust in Organizations. Frontiers of Theory and Research, Sage, Thousand Oaks, 114-139.

[38] Kramer, R.M. and Lewicki, R.J. (2010) Repairing and Enhancing Trust: Approaches to Reducing Organizational Trust Deficits. Academy of Management Annals, 4, 245-277. https://doi.org/10.5465/19416520.2010.487403

[39] Moss, T.W., Neubaum, D.O. and Meyskens, M. (2015) The Effect of Virtuous and Entrepreneurial Orientations on Microfinance Lending and Repayment: A Signaling Theory Perspective. Entrepreneurship Theory and Practice, 39, 27-52. https://doi.org/10.1111/etap.12110

[40] Pittaway, L. and Cope, J. (2007) Entrepreneurship Education: A Systematic Review of the Evidence. International Small Business Journal, 25, 479-510. https://doi.org/10.1177/0266242607080656

[41] Henry, C. and Foss, L. (2014) Case Sensitive? A Review of the Literature on the Use of Case Method in Entrepreneurship Research. International Journal of Entrepreneurial Behavior \& Research, 21, 389-409. 
https://doi.org/10.1108/IJEBR-03-2014-0054

[42] Dawson, A. and Mussolino, D. (2014) Exploring What Makes Family Firms Different: Discrete or Overlapping Constructs in the Literature? Journal of Family Business Strategy, 5, 169-183. https://doi.org/10.1016/j.jfbs.2013.11.004

[43] Gabarro, J.J. (1978) The Development of Trust Influence and Expectations. In: Athos, A.G. and Gabarro, J.J., Eds., Interpersonal Behavior. Communication and Understanding in Relationships, Prentice Hall, Englewood Cliffs, 290-303.

[44] Butler, J.K. (1991) Toward Understanding and Measuring Conditions of Trust: Evolution of a Conditions of Trust Inventory. Journal of Management, 17, 643-663. https://doi.org/10.1177/014920639101700307

[45] Altinay, L., Saunders, M.N.K. and Wang, C.L. (2014) The Influence of Culture on Trust Judgments in Customer Relationship Development by Ethnic Minority Small Businesses. Journal of Small Business Management, 52, 59-78. https://doi.org/10.1111/jsbm.12033

[46] Curtis, T., Herbst, J. and Gumkovska, M. (2010) The Social Economy of Trust: Social Entrepreneurship Experiences in Poland. Social Enterprise Journal, 6, 194-209. https://doi.org/10.1108/17508611011088805

[47] Howorth, C. and Moro, A. (2012) Trustworthiness and Interest Rates: An Empirical Study of Italian SMEs. Small Business Economics, 39, 161-177. https://doi.org/10.1007/s11187-010-9285-4

[48] Moro, A., Fink, M. and Kautonen, T. (2014) How Do Banks Assess Entrepreneurial Competence? The Role of Voluntary Information Disclosure. International Small Business Journal, 32, 525-544. https://doi.org/10.1177/0266242612458444

[49] Scarbrough, H., Swan, J., Amaeshi, K. and Briggs, T. (2013) Exploring the Role of Trust in the Deal-Making Process for Early-Stage Technology Ventures. Entrepreneurship Theory and Practice, 37, 1203-1228. https://doi.org/10.1111/etap.12031

[50] Payne, G.T., Davis, J.L., Moore, C.B. and Bell, R.G. (2009) The Deal Structuring Stage of the Venture Capitalist Decision-Making Process: Exploring Confidence and Control. Journal of Small Business Management, 47, 154-179. https://doi.org/10.1111/j.1540-627X.2009.00266.x

[51] Schwarzkopf, J., Lévesque, M. and Maxwell, A. (2010) How Entrepreneurs-in-Residence Increase Seed Investment Rates. Venture Capital. An International Journal of Entrepreneurial Finance, 12, 65-81. https://doi.org/10.1080/13691060903435783

[52] Bergh, P., Thorgren, S. and Wincent, J. (2011) Entrepreneurs Learning Together: The Importance of Building Trust for Learning and Exploiting Business Opportunities. 17-37. https://doi.org/10.1007/s11365-009-0120-9

[53] Kelly, P. and Hay, M. (2003) Business Angel Contracts: The Influence of Context. Venture Capital. An International Journal of Entrepreneurial Finance, 5, 287-312. https://doi.org/10.1080/1369106032000141940

[54] Rhee, R.J. and White, K.S. (2007) The Emotional Intelligence of Entrepreneurs. Journal of Small Business and Entrepreneurship Development, 20, 409-425. https://doi.org/10.1080/08276331.2007.10593408

[55] Lehto, I. (2015) International Entrepreneurial Selling as Construction of International Opportunities. Journal of International Entrepreneurship, 13, 277-302. https://doi.org/10.1007/s10843-015-0147-7

[56] Sengupta, A. (2011) Network Strategy and Access to Business Finance. The Journal of Entrepreneurship, 20, 103-126. https://doi.org/10.1177/097135571002000105

[57] Lopes, M.P., Pina, M., Cunha, E. and Da Palma, P.J. (2009) Case Studies on What 
Entrepreneurs Actually Do to Attract Resources: A Two-Route Framework. Journal of Enterprising Culture, 17, 323-349. https://doi.org/10.1142/S0218495809000394

[58] Bowey, J.L. and Easton, G. (2007) Entrepreneurial Social Capital Unplugged: An Activity-Based Analysis. International Small Business Journal, 25, 273-306. https://doi.org/10.1177/0266242607076528

[59] Jack, S.L. and Anderson, A.R. (2002) The Effects of Embeddedness on the Entrepreneurial Process. Journal of Business Venturing, 17, 467-487. https://doi.org/10.1016/S0883-9026(01)00076-3

[60] Holt, R. and Macpherson, A. (2010) Sensemaking, Rhetoric and the Socially Competent Entrepreneur. International Small Business Journal, 28, 20-42. https://doi.org/10.1177/0266242609350822

[61] De Clercq, D. and Sapienza, H.J. (2006) Effects of Relational Capital and Commitment on Venture Capitalists' Perception of Portfolio Company Performance. Journal of Business Venturing, 21, 326-347. https://doi.org/10.1016/j.jbusvent.2005.04.007

[62] Altinay, L. (2008) The Relationship between an Entrepreneur's Culture and the Entrepreneurial Behaviour of the Firm. Journal of Small Business and Enterprise Development, 15, 111-129. https://doi.org/10.1108/14626000810850874

[63] Jones, R. and Rowley, J. (2011) Networks and Customer Relationships in a Small Software Technology Firm: A Case Study. Journal of Small Business and Entrepreneurship Development, 24, 29-48. https://doi.org/10.1080/08276331.2011.10593524

[64] Jean, L.S.K. and Tan, F. (2001) Growth of Chinese Family Enterprises in Singapore. Family Business Review, 14, 49-74. https://doi.org/10.1111/j.1741-6248.2001.00049.x

[65] Jansson, J. (2011) Emerging (Internet) Industry and Agglomeration: Internet Entrepreneurs Coping with Uncertainty. Entrepreneurship \& Regional Development, 23, 499-521. https://doi.org/10.1080/08985620903505987

[66] MacDougall, S.L. and Hurst, D. (2007) Surviving the Transience of Knowledge: Small High-Technology Businesses Parting Ways with Their Knowledge Workers. Journal of Small Business and Entrepreneurship Development, 20, 183-199. https://doi.org/10.1080/08276331.2007.10593394

[67] Lee, R. and Jones, O. (2008) Networks, Communication and Learning during Business Start-Up: The Creation of Cognitive Social Capital. International Small Business Journal, 26, 559-594. https://doi.org/10.1177/0266242608094030

[68] Cruickshank, P. and Rolland, D. (2006) Entrepreneurial Success through Networks and Social Capital: Exploratory Considerations from GEM Research in New Zealand. Journal of Small Business and Entrepreneurship Development, 19, 63-80. https://doi.org/10.1080/08276331.2006.10593359

[69] Jonsson, S. (2015) Entrepreneurs' Network Evolution-The Relevance of Cognitive Social Capital. International Journal of Entrepreneurial Behavior \& Research, 21, 197-223. https://doi.org/10.1108/IJEBR-09-2013-0147

[70] Amatucci, F.M. and Sohl, J.E. (2004) Women Entrepreneurs Securing Business Angel Financing: Tales from the Field. Venture Capital: An International Journal of Entrepreneurial Finance, 6, 181-196. https://doi.org/10.1080/1369106042000223579

[71] Totterman, H. and Sten, J. (2005) Start-Ups: Business Incubation and Social Capital. International Small Business Journal, 23, 487-511. https://doi.org/10.1177/0266242605055909

[72] Van Gelderen, M. (2010) A Heuristic-Inducing Method for Generating Initial Ideas 
for Opportunities: An Application to the Australasian Dating Market. Journal of Enterprising Culture, 18, 139-166. https://doi.org/10.1142/S0218495810000525

[73] Presutti, M., Boari, C. and Majocchi, A. (2011) The Importance of Proximity for the Start-Ups' Knowledge Acquisition and Exploitation. Journal of Small Business Management, 49, 361-389. https://doi.org/10.1111/j.1540-627X.2011.00331.x

[74] Doern, R. and Goss, D. (2012) From Barriers to Barring: Why Emotion Matters for Entrepreneurial Development. International Small Business Journal, 31, 496-519. https://doi.org/10.1177/0266242611425555

[75] Welter, F., Kautonen, T., Chepurenko, A., Malieva, E. and Venesaar, U. (2004) Trust Environments and Entrepreneurial Behavior-Exploratory Evidence from Estonia, Germany and Russia. Journal of Enterprising Culture, 12, 327-349. https://doi.org/10.1142/S0218495804000178

[76] Sarpong, D. and Davies, C. (2014) Managerial Organizing Practices and Legitimacy Seeking in Social Enterprises. Social Enterprise Journal, 10, 21-37. https://doi.org/10.1108/SEJ-05-2013-0019

[77] Weber, C. and Weber, B. (2011) Exploring the Antecedents of Social Liabilities in CVC Triads-A Dynamic Social Network Perspective. Journal of Business Venturing, 26, 255-272. https://doi.org/10.1016/j.jbusvent.2009.07.004

[78] Gordon, I. and Jack, S. (2010) HEI Engagement with SMEs: Developing Social Capital. International Journal of Entrepreneurial Behavior \& Research, 16, 517-539. https://doi.org/10.1108/13552551011082489

[79] Sigfusson, T. and Harris, S. (2012) The Relationship Formation Paths of International Entrepreneurs. Journal of International Entrepreneurship, 10, 325-349. https://doi.org/10.1007/s10843-012-0095-4

[80] Drnovsek, M., Zorn, O. and Martincic, M. (2008) Responsible Entrepreneurs: The Network Effects. Journal of Enterprising Culture, 16, 209-231. https://doi.org/10.1142/S0218495808000168

[81] Ren, S., Shu, R., Bao, Y. and Chen, X. (2014) Linking Network Ties to Entrepreneurial Opportunity Discovery and Exploitation: The Role of Affective and Cognitive Trust. International Entrepreneurship and Management Journal, 12, 465-485. https://doi.org/10.1007/s11365-014-0350-3

[82] Nwankwo, S. and Gbadamosi, A. (2013) Faith and Entrepreneurship among the British African-Caribbean: Intersections between Religious and Entrepreneurial Values. Journal of Small Business and Enterprise Development, 20, 618-633. https://doi.org/10.1108/JSBED-04-2013-0066

[83] Phillips, N., Tracey, P. and Karra, N. (2013) Building Entrepreneurial Tie Portfolios through Strategic Homophily: The Role of Narrative Identity Work in Venture Creation and Early Growth. Journal of Business Venturing, 28, 134-150. https://doi.org/10.1016/j.jbusvent.2011.12.002

[84] Ingstad, E.L., Knockaert, M. and Fassin, Y. (2014) Smart Money for Social Ventures: An Analysis of the Value-Adding Activities of Philanthropic Venture Capitalists. Venture Capital: An International Journal of Entrepreneurial Finance, 16, 349-378. https://doi.org/10.1080/13691066.2014.988379

[85] McAdam, M. and Marlow, S. (2007) Building Futures or Stealing Secrets? Entrepreneurial Cooperation and Conflict within Business Incubators. International Small Business Journal, 25, 361-382. https://doi.org/10.1177/0266242607078563

[86] Ariño, P.M., Torre, A. and Ring, J. (2001) Relational Quality: Managing Trust in Corporate Alliances. California Management Review, 44, 109-131. 
https://doi.org/10.2307/41166113

[87] Freiburg, M. and Grichnik, D. (2012) Institutional Investments in Private Equity Funds: Social Ties and the Reduction of Information Asymmetry. Venture Capital: An International Journal of Entrepreneurial Finance, 14, 1-26. https://doi.org/10.1080/13691066.2011.642147

[88] Mcknight, D.H. and Chervany, N.L. (2006) Reflections on an Initial Trust-Building Model. In: Bachmann, R. and Zaheer, A., Eds., Handbook of Trust Research, Edward Elgar, Cheltenham, 29-51.

[89] Sørheim, R. (2005) Business Angels as Facilitators for Further Finance: An Exploratory Study. Journal of Small Business and Enterprise Development, 12, 178-191. https://doi.org/10.1108/14626000510594593

[90] Blois, K.J. (1999) Trust in Business to Business Relationships: An Evaluation of Its Status. Journal of Management Studies, 36, 197-215. https://doi.org/10.1111/1467-6486.00133

[91] Ravasi, D. and Marchisio, G. (2003) Going Public and the Enrichment of a Supportive Network. Small Business Economics, 21, 381-395. https://doi.org/10.1023/A:1026119221991

[92] Nikolova, N., Möllering, G. and Reihlen, M. (2015) Trusting as a "Leap of Faith": Trust-Building Practices in Client-Consultant Relationships. Scandinavian Journal of Management, 31, 232-245. https://doi.org/10.1016/j.scaman.2014.09.007 
Annex 1. Reading guide.

\begin{tabular}{|c|c|c|c|c|c|c|c|c|c|c|c|}
\hline Author & Year & Journal & Stakeholder & Theory & Country & $\begin{array}{l}\text { Trust } \\
\text { definition }\end{array}$ & Method & Sample & Respondents & \multicolumn{2}{|l|}{ Findings } \\
\hline $\begin{array}{l}\text { Howorth } \\
\text { and } \\
\text { Moro }\end{array}$ & 2006 & $\begin{array}{l}\text { Entrepreneurship } \\
\text { Theory and } \\
\text { Practice }\end{array}$ & Bank & $\begin{array}{l}\text { Theory } \\
\text { of trust }\end{array}$ & Italy & $\begin{array}{l}\text { "The } \\
\text { willingness } \\
\text { of a party to } \\
\text { be vulnerable } \\
\text { to the actions } \\
\text { of another } \\
\text { party on the } \\
\text { expectation } \\
\text { that the other } \\
\text { will perform a } \\
\text { particular } \\
\text { action important } \\
\text { to the trustor, } \\
\text { irrespective } \\
\text { of the ability } \\
\text { to monitor or } \\
\text { control that party" } \\
\text { (Mayer } \\
\text { et al. 1995) }\end{array}$ & Interviews & 26 & $\begin{array}{l}20 \\
\text { entrepreneurs } \\
\text { and six bank } \\
\text { managers }\end{array}$ & \multicolumn{2}{|c|}{$\begin{array}{l}\text { Shared interests. Development } \\
\text { of shared beliefs and values. } \\
\text { To be a member of the board } \\
\text { of a very important } \\
\text { association. Understanding. } \\
\text { The congruence of values } \\
\text { between trustor and trustee. } \\
\text { To be very good at doing her } \\
\text { job. To Know her very well. } \\
\text { Personal links. Frequency of } \\
\text { interactions. To highlight the } \\
\text { importance of community } \\
\text { involvement. To be involved } \\
\text { and/or supportive of church } \\
\text { activity, being a member of the } \\
\text { city council ... To be a } \\
\text { member of the local } \\
\text { volunteering fire brigade or } \\
\text { volunteering emergency } \\
\text { service. The ethics and } \\
\text { principles of her. To } \\
\text { demonstrate his desire to do } \\
\text { good to others. Reputation. } \\
\text { Gossip }\end{array}$} \\
\hline $\begin{array}{l}\text { Sigfusson } \\
\text { and } \\
\text { Harris }\end{array}$ & 2012 & $\begin{array}{l}\text { Journal of } \\
\text { International } \\
\text { Entrepreneurship }\end{array}$ & $\begin{array}{l}\text { Partner and } \\
\text { competitors }\end{array}$ & $\begin{array}{l}\text { Network } \\
\text { theory }\end{array}$ & $\begin{array}{l}\text { Iceland } \\
\text { and } \\
\text { Scotland }\end{array}$ & $\begin{array}{l}\text { "One party has } \\
\text { confidence in } \\
\text { an exchange } \\
\text { partner's } \\
\text { reliability and } \\
\text { integrity" (Morgan } \\
\text { and Hunt 1994) }\end{array}$ & $\begin{array}{l}\text { Case } \\
\text { studies }\end{array}$ & 10 & Entrepreneurs & $\begin{array}{l}\text { Cognitive } \\
\text { aspects } \\
\text { Affective } \\
\text { aspects } \\
\text { Virtual “o } \\
\text { Good rep }\end{array}$ & $\begin{array}{l}\text { Value } \\
\text { Honesty } \\
\text { Reliance } \\
\text { Closeness } \\
\text { Family ties } \\
\text { ne" relationships } \\
\text { tion }\end{array}$ \\
\hline $\begin{array}{c}\text { Welter } \\
\text { et al. }\end{array}$ & 2004 & $\begin{array}{l}\text { Journal of } \\
\text { Enterprising } \\
\text { Culture }\end{array}$ & Partner & $\begin{array}{l}\text { Game } \\
\text { theory }\end{array}$ & $\begin{array}{l}\text { Estonia, } \\
\text { Germany } \\
\text { and Russia }\end{array}$ & $\begin{array}{l}\text { "A record of prior } \\
\text { exchange, often } \\
\text { obtained indirectly } \\
\text { by imputation } \\
\text { from outcomes of } \\
\text { prior exchange } \\
\text { provides data } \\
\text { on the exchange } \\
\text { process" (Zucker, } \\
\text { 1986) }\end{array}$ & Survey & 197 & Enterprise & $\begin{array}{l}\text { Friends. } \\
\text { payment } \\
\text { Knowledg } \\
\text { the partne } \\
\text { Recomme } \\
\text { Reputatio } \\
\text { customer/ } \\
\text { Personal } 1\end{array}$ & $\begin{array}{l}\text { rantees for } \\
\text { I delivery. } \\
\text { f and about } \\
\text { ation. } \\
\text { f the } \\
\text { ppliers. } \\
\text { work }\end{array}$ \\
\hline
\end{tabular}

Annex 2. Coding guide.

\begin{tabular}{|c|c|c|c|c|}
\hline Factor & Antecedent & Dimension & Definition & References \\
\hline \multirow[t]{5}{*}{ Ability } & \multicolumn{2}{|c|}{ Business sense } & $\begin{array}{l}\text { Common sense and wisdom about how a business } \\
\text { works }\end{array}$ & $\begin{array}{l}\text { Gabarro, 1978; Butler, 1991; Mayer et al., } \\
1995\end{array}$ \\
\hline & \multicolumn{2}{|c|}{ Capable experience } & $\begin{array}{l}\text { Demonstrates relevant work and/or training } \\
\text { experience } \\
\text { Perceived expertise }\end{array}$ & $\begin{array}{l}\text { Mayer et al., 1995; Maxwell and Levesque, } \\
2014\end{array}$ \\
\hline & \multicolumn{2}{|c|}{$\begin{array}{l}\text { Functional/ } \\
\text { specific competence }\end{array}$} & Knowledge and skills related to a specific task & $\begin{array}{l}\text { Gabarro, 1978; Butler, 1991; Mayer et al., } \\
\text { 1995; Maxwell and Levesque, } 2014\end{array}$ \\
\hline & & Knowledge & \multicolumn{2}{|c|}{ To recall facts, concepts, principles and procedures within certain domains } \\
\hline & & Skills & \multicolumn{2}{|c|}{ To have acquired a proficiency in the execution of operations to achieve a certain goal state } \\
\hline
\end{tabular}




\section{Continued}

Competence

Interpersonal competence

Judgment

Benevolence Accuracy

Availability

Disclosure

Explanation

Loyalty

Motives

Openness in

Openness out

Receptivity

Reliance

Integrity Alignment

Value congruence

Common goals and shared value

Consistency
People skills

Ability to make accurate, objective and good decisions

To provide truthful and timely information

Being physically present when needed Availability approachable and reachable

To show vulnerability by sharing confidential information

To explain details and consequence of information provided

An implicit promise from a subordinate not to bring harm to the executive. Having motives for protecting and making the target person look good.

Demotivation to lie. Altruism. Not knowingly do anything to hurt me. Protect. Willingness to help-to give support

Intentions and agenda. Positive attitude. Courtesy. To want to do good. To exhibit concern about well-being of others

Open to new ideas or new ways of doing things

Leveling and expressing ideas freely

Mentally open and receptive. Accessibility. Being to the giving and accepting of ideas. To demonstrate willingness to accept others' influence (e.g., by being "coachable") and willingness to change

To show willingness to be vulnerable through delegation of tasks

Adherence and acceptability to a set of principles

The compatibility of an employee's beliefs and values with the organization's cultural values

Action confirms shared values and/or objectives

The extent to which the party's actions are congruent Gabarro, 1978; Butler, 1991; Mayer et al., with his or her words

To follow up on any appointment and commitments

Reliability encountered situation

Acting and making decisions consistently, in such a

Predictability way as to prevent others' anxiety caused by the unexpected
1995; Maxwell and Levesque, 2014

Gabarro, 1978; Butler, 1991; Mayer et al., 1995

Gabarro, 1978; Butler, 1991; Mayer et al., 1995; Maxwell and Levesque, 2014

Maxwell and Levesque, 2014

Butler, 1991; Mayer et al., 1995

Maxwell and Levesque, 2014

Mayer et al., 1995; Maxwell and

Levesque, 2014 [14]

Butler, 1991; Mayer et al., 1995

Gabarro, 1978; Mayer et al., 1995;

Maxwell and Levesque, 2014

Maxwell and Levesque, 2014

Gabarro, 1978; Butler, 1991; Mayer et al., 1995

Butler, 1991; Mayer et al., 1995; Maxwell and Levesque, 2014

Maxwell and Levesque, 2014

Maxwell and Levesque, 2014; Mayer et al., 1995

Mayer et al., 1995

Maxwell and Levesque, 2014; Mayer et al., 1995

Mayer et al., 1995

Gabarro, 1978; Butler, 1991 


\section{Continued}

Promise fulfillment

Discreetness

Fairness

Honesty

Moral character
When I agree on something I know he will stay to his word

Keeping confidences

To treat people equal and strong sense of justice

Sincere, cannot be corrupted and truthfulness

The intrinsic moral norms a trustee guards her actions with
Butler, 1991; Mayer et al., 1995

Gabarro, 1978; Butler, 1991; Mayer et al., 1995

Butler, 1991; Mayer et al., 1995

Mayer et al., 1995; Gabarro, 1978; Butler, 1991

Gabarro, 1978; Butler, 1991; Mayer et al., 1995 